\title{
Enhancing crop yield by using Rubisco activase to improve photosynthesis under elevated temperatures
}

\author{
Inosha Wijewardene ${ }^{1 *}$, Guoxin Shen ${ }^{2}$ and Hong Zhang ${ }^{1 *}$
}

\begin{abstract}
With the rapid growth of world population, it is essential to increase agricultural productivity to feed the growing population. Over the past decades, many methods have been used to increase crop yields. Despite the success in boosting the crop yield through these methods, global food production still needs to be increased to be on par with the increasing population and its dynamic consumption patterns. Additionally, given the prevailing environmental conditions pertaining to the global temperature increase, heat stress will likely be a critical factor that negatively affects plant biomass and crop yield. One of the key elements hindering photosynthesis and plant productivity under heat stress is the thermo-sensitivity of the Rubisco activase (RCA), a molecular chaperone that converts Rubisco back to active form after it becomes inactive. It would be an attractive and practical strategy to maintain photosynthetic activity under elevated temperatures by enhancing the thermo-stability of RCA. In this context, this review discusses the need to improve the thermo-tolerance of RCA under current climatic conditions and to further study RCA structure and regulation, and its limitations at elevated temperatures. This review summarizes successful results and provides a perspective on RCA research and its implication in improving crop yield under elevated temperature conditions in the future.
\end{abstract}

Keywords: Climate change, Drought, Heat stress, Temperature increase, Rubisco activase

\section{The issue at hand: the rising atmospheric temperatures}

With the projected population to exceed 9 billion by 2050 and the global mean temperature rising by $1.5^{\circ} \mathrm{C}$, worldwide agricultural productivity needs to be increased by at least $60 \%$ or more amidst the changing climate, declining cropland and limited freshwater to sustain food production (Dubey et al. 2020). If the current trend of escalating temperature continues and goes up by $1.5^{\circ} \mathrm{C}$ or more, the food productivity in the world, especially in the subSaharan Africa, Latin America, and parts of Asia, is expected to decrease, which would lead to serious consequences on food availability to people in those regions

\footnotetext{
*Correspondence: noshisw@gmail.com; hong.zhang@ttu.edu

1 Department of Biological Sciences, Texas Tech University, Lubbock, TX

79409, USA

Full list of author information is available at the end of the article
}

(Ipcc IPOCC and Bongaarts 2019). Therefore, despite that certain cooler regions of the world might benefit from this temperature increase, as a whole, the global agricultural scenario would still look negative in terms of productivity (Fahad et al. 2017).

Abiotic stresses such as drought, extreme temperatures (e.g. heat, chilling, and freezing), salinity, and floods account for more than $50 \%$ of the annual crop loss globally, which could increase to an even greater extent with the severity and frequency of adverse climatic changes (Minhas et al. 2017). Heat stress in particular leads to several consequences, for instance the soil temperature increasing due to high air temperature, subsequently causing a depletion in soil moisture, thereby exacerbating the severity of the heat stress (Akter and Islam 2017). Ultimately, critical activities of plants including seed germination, growth and development, 
pollen production, and photosynthesis are all unfavorably affected, resulting in poor crop yield (Rollins et al. 2013; Nadeem et al. 2018). For example, a recent study that evaluated 30 wheat cultivation sites across the world from 1981 to 2010 showed that there was a $1-28 \%$ and 6-55\% yield reduction when there were temperature increases of 2 and $4{ }^{\circ} \mathrm{C}$, respectively, indicating that for every $1{ }^{\circ} \mathrm{C}$ increase in atmospheric temperature, roughly $6 \%$ of yield reduction would be experienced in global wheat production (Akter and Islam 2017). Thus, it is imperative to investigate and explore strategies to improve agriculture production under heat stress conditions and select and breed thermo-tolerant cultivars as well as use molecular and genetic methods to create thermotolerant varieties that will be able to thrive and provide substantially higher yields under sub-optimal environmental conditions.

\section{Scope of genetic engineering in improving plant heat stress tolerance}

Exploring the possibilities of improving plant biomass and productivity under elevated temperatures is vital to keep up with the demand of the growing population. In addition to unfavorable weather conditions such as heat stress, food production will be under the constraints of less water, less land, less labor, and less chemicals such as fertilizers and pesticides. The genetic engineering approach appears to be an effective alternative strategy to improve crop yield in the future alongside traditional breeding methods (Khush 2005; Nalluri and Karri 2020). Incorporation of the genetic engineering techniques could aid in overcoming several limitations of conventional breeding practices, and these limitations include the long time needed to introduce a new variety, the labor intensive screening of hundreds or thousands of varieties in replicated plot trials, and the introduction of undesirable traits along with the desirable characteristics (Ulukan 2009). Additionally, with smart farming or what is considered as the fourth revolution in agriculture, which utilizes information and communication technology to evaluate various field parameters such as biomass development calculation, soil and crop fertilizer status, irrigation requirement and potential soil leaching issues, sustainable agricultural practices will be a reality with the minimum use of resources instead of overexploitation (Walter et al. 2017). Therefore, adopting molecular approaches such as genetic engineering and gene editing to introduce thermo-tolerant crop varieties is an effective solution towards increasing crop yield through sustainable agricultural practices that would be worth of further exploration.

Among the numerous genetic engineering efforts tried over the years, overexpression of genes to enhance plant performance under moderate to high heat stress conditions has shown to be a successful approach (Singh et al. 2019). A variety of candidate genes have been introduced into different plants where varying degrees of increased heat tolerance have been achieved in the transgenic lines. The functions of the genes that were introduced into transgenic plants span across a diverse collection of activities such as transcription factors (Qi et al. 2018; El-Esawi et al. 2019), quantitative trait loci related to heat stress (Acuña-Galindo et al. 2015; Wen et al. 2019), heat shock proteins (HSPs)/chaperone proteins (Panzade et al. 2020; Wang et al. 2020), heat shock factors (HSFs) (Wang et al. 2017), osmolytes (Cvikrová et al. 2012), regulatory proteins participating in oxidative stress signaling (Lin et al. 2015; Ali et al. 2020; Ghosh et al. 2020), hormonal signaling (Bi et al. 2020), and abiotic stress response pathways (Zang et al. 2017; Lamaoui et al. 2018; Nadeem et al. 2018). Among these approaches, studies related to the photosynthetic machinery would seem like a winning strategy since the efficiency of photosynthesis ultimately determines plant biomass and yield, which makes sense in an economical scale and it directly translates into increased productivity (Antonovsky et al. 2017). At present, relatively limited work has been carried out in manipulating the components in the primary carbon assimilation pathway, i.e. the Calvin Benson Cycle enzymes, especially modifications to the key enzyme, ribulose-1,5-bisphosphate carboxylase-oxygenase (Rubisco) are scarce, due to the structural complexity of this enzyme complex, drawbacks of labor-intensive and time-consuming factors involved, the possibility of impairing plant growth and development, and deleterious consequences of the molecular manipulation (Wilson et al. 2019).

Although numerous studies have attempted to improve photosynthesis through methods such as overexpressing Rubisco subunits, and altering Rubisco properties or its catalytic features, enhanced photosynthetic rates could not be achieved (Suzuki et al. 2009; Wostrikoff et al. 2012). However, in a recent study involving maize overexpressing Rubisco small subunit (UBI-SS), both Rubisco large and small subunits (UBI-LSSS), the Rubisco assembly chaperone RUBISCO ASSEMBLY FACTOR 1 (RAF1) (UBI-RAF1), and Rubisco large and small subunits plus RAF1 (UBI-LSSS-RAF1), the results demonstrated that Rubisco content was significantly increased in UBI-LSSSRAF1 plants compared to the other genotypes tested (Salesse-Smith et al. 2018). Moreover, the UBI-LSSSRAF1 plants showed significantly higher biomass and longer height as well as approximately a $15 \%$ increased $\mathrm{CO}_{2}$ assimilation rate compared to that of wild-type plant, indicating the important role played by Rubisco chaperone proteins in improving photosynthesis. Also, the work conducted by Yoon et al. (2020) involving Rubisco overproducing (RBCS-sense) and Rubisco antisense (RBCSantisense) rice plants, which had $130 \%$ and $35 \%$ of wild- 
type Rubisco levels, respectively, showed that dry weight, yield and nitrogen use efficiency (NUE) of the RBCS-sense plants were significantly increased upon sufficient nitrogen-fertilizer application, where the above parameters were higher at $15.0 \mathrm{Nm}^{-2}$ fertilizer application relative to $10.0 \mathrm{Nm}^{-2}$ fertilizer plot in the experimental paddy field (Yoon et al. 2020). In contrast, regardless of the $\mathrm{N}$ application, the yield of $R B C S$-antisense plants was significantly lower than wild-type rice plants. Additionally, the RBCSsense plants displayed a greater biomass than wild-type plants at harvesting stage due to better NUE and higher N absorption, ultimately relating to improved yield, which was not shown by the $R B C S$-antisense plants, indicating that with sufficient nitrogen supply, the overexpression of Rubisco leads to enhanced photosynthesis per unit leaf area and improved yield. Nonetheless, considering the fact that the yield could not be improved under low $\mathrm{N}$ supply despite overexpression of Rubisco subunits only, it is implied that increasing yield and biomass of crops requires several contributors working together in order to bring a significant increase in productivity. Overuse of $\mathrm{N}$ in agriculture leads to various undesirable environmental consequences including eutrophication, while overproduction of Rubisco could cost plant to allocate more $\mathrm{N}$ for $\mathrm{Ru}$ bisco, limiting or depriving other components in plant for access to nitrogen, which could eventually limit photosynthesis (Parry et al. 2003; Parry et al. 2007). Thus, it must be with great care and precision that plant productivity should be improved through interfering with the photosynthetic process, where exceptional understanding on photosynthesis is warranted to bring about a meaningful benefit in improving the plant yield via genetic engineering methods.

\section{Photosynthesis: a critical process affected by heat stress}

Photosynthesis is a process that plays a critical role in plant growth and development, which directly translates into plant biomass and/or yield (Fan et al. 2018), while being one of the most heat sensitive cellular activities taking place inside chloroplast (Allakhverdiev et al. 2008). Heat stress could be described as an increase in temperature above a given limit that remains for a period of time, resulting in the irreversible damages in photosynthetic machinery, cellular structures and plant metabolism (Wahid et al. 2007). A heat shock or heat stress is created when the ambient temperature transiently rises by $10-15^{\circ} \mathrm{C}$, which could greatly affect the proper functioning of a plant. Depending on its duration, intensity, and rate of temperature increase, moderate to high heat stresses cause catastrophic events, directly affecting the photosynthetic process such as increased thylakoid membrane fluidity, aggregation, denaturation or degradation of proteins, and inactivation of enzymes, thereby compromising the overall efficiency of photosynthesis (Sharkey 2005). Consequently, exploring the possibilities of successfully introducing genes related to photosynthesis into plant genome to increase their thermo-tolerance holds great potential in enhancing photosynthesis-led increase in crop yield.

\section{Rubisco and photosynthesis}

Under optimum conditions, $\mathrm{CO}_{2}$ binds to the active site of the most abundant protein on earth, Rubisco, in a process called carbamylation, followed by the binding of $\mathrm{Mg}^{2+}$, which is essential for the enzyme's catalytic activity (Salvucci and Ogren 1996). Next, the substrate ribulose-1,5-bisphosphate (RuBP) binds to the carbamylated Rubisco (Fig. 1). However, various sugar phosphate molecules other than RuBP, could also bind to the active site of carbamylated or uncarbamylated Rubisco, leading to the formation of stable inactive forms of the enzymesubstrate complex (Fig. 1) (Portis Jr and Salvucci 2002). For example, certain inhibitory sugar phosphates, of which carboxyarabinitol 1-phosphate (CA1P) and 3ketoarabinitol bisphosphate (3KABP) are the most common, could firmly bind to the carbamylated Rubisco, functioning as competitive inhibitors of RuBP, thereby preventing its interaction with the Rubisco active site (Fig. 1). Also, during the Rubisco reaction, molecules such as enediol intermediates get converted to XuBP (xylulose-1,5-bisphosphate) at the active site as a result of misprotonation, giving rise to catalytic misfires, a process which increases under heat stress (Salvucci and Crafts-Brandner 2004). Consequently, all these activities hinder the catalytic efficiency of Rubisco, causing a decrease in photosynthetic rate (Portis 2003). Interestingly, despite these obstacles Rubisco still exhibits $70-100 \%$ of activity, which was attributed to the activity of Rubisco activase (RCA) that allows Rubisco to efficiently function under physiological conditions (Portis Jr 1990). While Rubisco kinetics predominantly directs the photosynthetic efficiency at low temperatures, under high temperatures, both Rubisco kinetics as well as its active state determine the photosynthetic performance (Yamori et al. 2006).

Of vital importance is the fact that as the temperature rises beyond optimum, the rate of Rubisco inactivation increases than the rate of Rubisco activation driven by the RCA activity, leading to a net negative effect in $\mathrm{Ru}$ bisco activation (Salvucci and Crafts-Brandner 2004). Stated simply, even though Rubisco, the principal enzyme in photosynthesis remains relatively stable at higher temperatures, the progressive loss of the ATPase activity of RCA due to its heat sensitivity, hampers the rate of photosynthesis as the temperature increases, causing a net effect of Rubisco inactivation under heat stress conditions (Law and Crafts-Brandner 1999; 


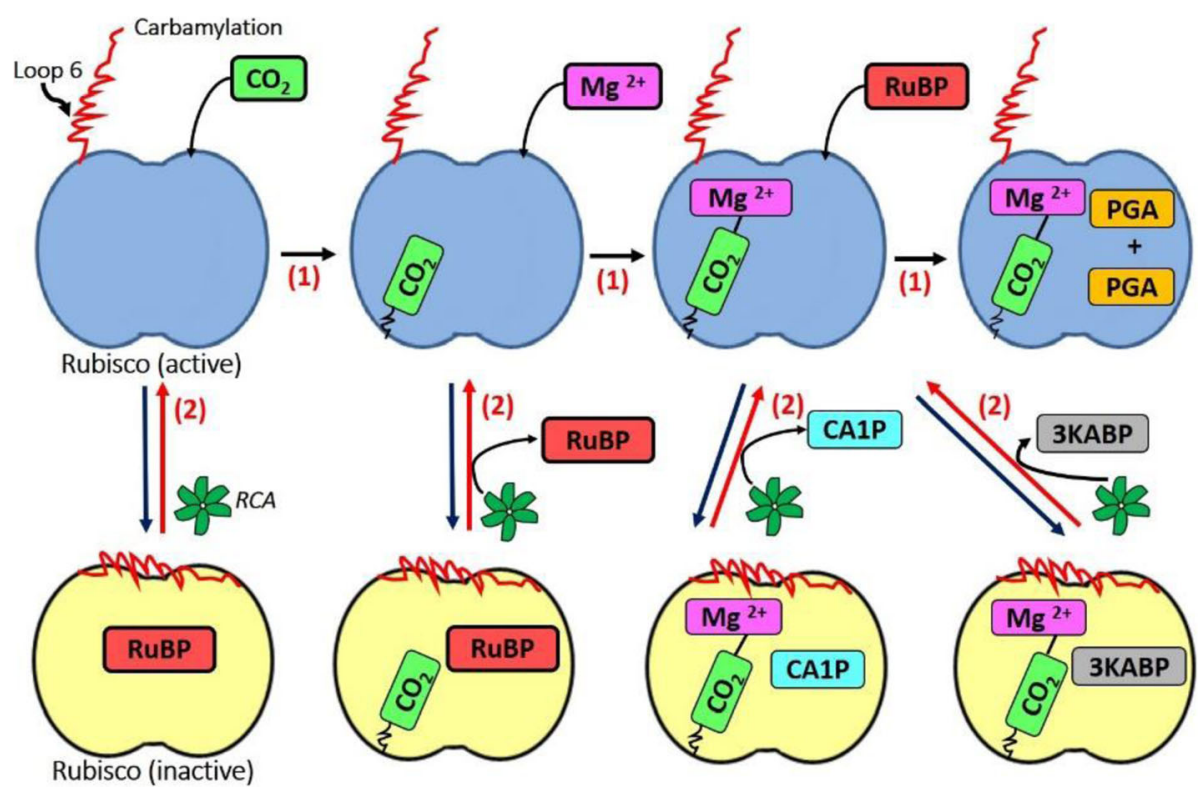

Fig. 1 A model on the mechanism of activation of Rubisco by RCA. Under normal conditions (i.e. optimal temperature for RCA), the sequential entry of substrates, i.e. firstly $\mathrm{CO}_{2}$ (a process called carbamylation), then a divalent metal $\mathrm{Mg}^{2+}$, followed by ribulose 1,5-bisphosphate (RuBP), leading to the production of two molecules of 3-phosphoglycerate (PGA) by Rubisco (see upper sequential steps marked by 1). However, Rubisco can frequently become inactive by converting itself into a conformation called closed state (yellow colored Rubisco in the figure), especially if RuBP enters the active site first or other sugars such as 2-carboxyarabinitol 1- phosphate (CA1P) and 3-ketoarabinitol bisphosphate (3KABP) enter the active site, which could lead to the formation of the closed state. The function of RCA is to convert the closed state of Rubisco back to its active conformation, i.e. open state (reactions marked by 2), which allows the wrong molecules trapped in the active site to be released and the right substrates to enter the active site so that $\mathrm{CO}_{2}$ fixation could proceed normally

Crafts-Brandner and Salvucci 2000; Salvucci and CraftsBrandner 2004b; Kim and Portis Jr 2005).

\section{The key player in Rubisco activation: Rubisco activase}

Rubisco activase was initially discovered while conducting experiments to isolate photorespiratory mutants in Arabidopsis thaliana, through the identification of a nuclear gene mutant $r c a$ (regulation of carboxylase activation), where unlike the wild-type, the $r c a$ mutant could not activate Rubisco under in vivo conditions (Somerville et al. 1982). Upon further investigation, it was observed that the rca mutant was deficient of two polypeptides, roughly 47 and $43 \mathrm{kDa}$, relative to the wild-type in the two-dimensional polyacrylamide gel electrophoresis, in the soluble polypeptides from the chloroplast fraction of Arabidopsis plants (Portis Jr 1990). Subsequent experiments revealed that these polypeptides were essential in the Rubisco activation process (Somerville et al. 1982) and was later named as Rubisco activase (Salvucci et al. 1985). Corresponding to the different types of Rubisco enzymes such as green- and redtype, RCA has been identified in photosynthetic organisms from chemoautotrophic bacteria to dicots (Salvucci et al. 1987; Tsai et al. 2015; Loganathan et al. 2016). Rubisco activase is considered as a type of molecular chaperone (Demirevska-Kepova et al. 2005) that controls the activation and inactivation of another protein, since it binds to the substrate protein Rubisco, where through this controlled binding, RCA stabilizes and regulates the correct conformation of Rubisco, ensuring that sugarphosphates are less tightly bound to Rubisco, enabling their release (Salvucci and Ogren 1996).

\section{RCA: structure, regulation, and its thermo-lability}

RCA is a member of the AAA+ ATPases (ATPases associated with diverse cellular activities), displaying a core twodomain architecture across prokaryotic and eukaryotic RCA, with a flexible $\alpha / \beta$-nucleotide binding subdomain at the $\mathrm{N}$-terminus and an $\alpha$-helical subdomain at the $\mathrm{C}$ terminus (Shivhare and Mueller-Cajar 2017b; Flecken et al. 2020). RCAs of plants and green algae also contain a Rubisco recognition domain $\mathrm{N}$-terminal to the AAA+ core while the ATPase activity is located near the extension at its $\mathrm{C}$-terminus, which is critical for its activity as shown by the loss of function mutant analyses (Bhat et al. 2017b). RCA has a hexameric ring structure approximately $45 \mathrm{kDa}$ in size, which requires a higher ATP/ADP ratio and free $\mathrm{Mg}^{2+}$ for accurate and efficient hexamer complex assembly (Kuriata et al. 2014). RCA commonly is made of two isoforms, arising either from a single gene via alternative splicing or separate genes (Werneke et al. 
1989). The highly redox sensitive long isoform $\alpha$ (45-46 $\mathrm{kDa}$ ) comprises a 40 amino acid C-terminal extension that includes a pair of cysteine residues, while the shorter isoform $\beta(41-43 \mathrm{kDa})$ shows no sensitivity to redox status (i.e. reduction/oxidation) (Shivhare et al. 2019). Several species including Arabidopsis, spinach, wheat, and rice have one RCA gene, whereas plants such as barley and cotton, sweet potato and tobacco contain two and three $R C A$ genes, respectively (Salvucci et al. 2003; Jiang et al. 2014) (Table 1), although another research showed that cotton, too, contains three RCA genes (Law et al. 2001). While at least one gene encoding RCA is present in all plants, during evolution, gene duplication events resulted in several copies of $R C A$ genes found in many plant species (Nagarajan and Gill 2018).

Numerous $R C A$ genes and isoforms have been studied in detail including spinach (Shen et al. 1991; Yamori et al. 2006), wheat (Law and Crafts-Brandner 2001), cotton (Salvucci et al. 2003), Arabidopsis (Salvucci et al. 2006), rice (Wang et al. 2010), maize (Yin et al. 2014), sweet potato (Jiang et al. 2013; Jiang et al. 2014), soybean (Chao et al. 2014), perennial ryegrass (Jurczyk et al. 2015a), and blue agave (Shivhare and Mueller-Cajar 2017a) (Table 1). In contrast, the regulation of $R C A$ gene expression remains to be further explored as the research done so far has only barely revealed the complexity of its regulatory mechanism. Promoter sequences of $R C A$ genes in several species have been investigated where a combination of cis- and trans-acting factors have been reported to control $R C A$ gene expression in addition to external cues such as light (Watillon et al. 1993; Qu et al. 2011; Zhang et al. 2016).

Additionally, the roles RCA isoforms could be slightly different to each other, even though they all carry out Rubisco activation. For example, the rice RCA isoform $\alpha$ mediates photosynthesis acclimation to moderate heat stress while initial Rubisco activation under ambient temperature is carried out by the isoform $\beta$ (Wang et al. 2010; Yin et al. 2014). In higher plants, $R C A$ gene expression is leaf age and light dependent and organ specific, where it is largely expressed in the photosynthetic tissues (Watillon et al. 1993; Liu et al. 1996). Its expression is diurnal, where the beginning of the photoperiod shows the maximal transcript level and the minimal transcript level during the mid-day, followed by an upsurge in the dark period. RCA functions in removing Rubisco-bound inhibitory sugar phosphates at the expense of ATP hydrolysis (Carmo-Silva and Salvucci 2011; Carmo-Silva et al. 2015). Hence, under normal irradiance, the $\mathrm{ATP} / \mathrm{ADP}$ ratio in the stroma is the chief regulator of the activase efficiency, however, if there is a co-expression of the two RCA isoforms, the chloroplast redox status is also involved in determining RCA activity (Ruuska et al. 2000; Zhang et al. 2002; Portis Jr et al. 2008; Henderson et al. 2011). Interestingly, in tobacco only the $\beta$ isoform gene is expressed despite the critical role played by the $\alpha$ isoform in other plants in response to redox regulation and fluctuating light (Yin et al. 2014;

Table 1 Examples of RCA genes and isoforms characterized in several plant species

\begin{tabular}{|c|c|c|c|}
\hline Plant & $\begin{array}{l}\text { Number } \\
\text { of genes }\end{array}$ & Number of isoforms & References \\
\hline $\begin{array}{l}\text { Arabidopsis } \\
\text { (Arabidopsis } \\
\text { thaliana) }\end{array}$ & One & Two or three: short isoform $\beta$ (RCA1), long isoform a (RCA2) & $\begin{array}{l}\text { (Zhang et al. 2001) (Kurek et al. 2007) (Kumar et al. } \\
\text { 2009) (Deridder et al. 2012) }\end{array}$ \\
\hline $\begin{array}{l}\text { Spinach (Spinacia } \\
\text { oleracea) }\end{array}$ & One & Two: short isoform (41 kDa) and long isoform (45 kDa) & $\begin{array}{l}\text { (Werneke et al. 1989) (Shen et al. 1991) (Crafts- } \\
\text { Brandner et al. 1997) }\end{array}$ \\
\hline Rice (Oryza sativa) & One & $\begin{array}{l}\text { Two: short isoform }\left(\mathrm{RCA}_{S}, 43 \mathrm{kDa}\right) \text { and long isoform }\left(\mathrm{RCA}_{\mathrm{L}}, 47\right. \\
\mathrm{kDa})\end{array}$ & $\begin{array}{l}\text { (To et al. 1999) (Zhang and Komatsu 2000) (Wang } \\
\text { et al. 2010) }\end{array}$ \\
\hline $\begin{array}{l}\text { Wheat (Triticum } \\
\text { aestivum) }\end{array}$ & Two & $\begin{array}{l}\text { Three: short isoform TaRca2- } \beta \text { ( } 42.2 \mathrm{kDa}) \text {, long isoform TaRca2- } \\
\text { a ( } 46 \mathrm{kDa}) \text { and short isoform TaRca1- } \beta \text { ( } 42.7 \mathrm{kDa})\end{array}$ & $\begin{array}{l}\text { (Carmo-Silva et al. 2015) (Kumar et al. 2016) } \\
\text { (Bayramov 2017) }\end{array}$ \\
\hline Maize (Zea mays) & Two & $\begin{array}{l}\text { Two or three: two short isoforms } \beta \text { ( } 41 \text { and } 43 \mathrm{kDa} \text { ) and a long } \\
\text { isoform a }(46.1 \mathrm{kDa})\end{array}$ & $\begin{array}{l}\text { (Martínez-Barajas et al. 1997) (Vargas-Suárez et al. } \\
\text { 2004) (Yin et al. 2014) (Ayala-Ochoa et al. 2004) }\end{array}$ \\
\hline $\begin{array}{l}\text { Barley (Hordeum } \\
\text { vulgare) }\end{array}$ & Two & $\begin{array}{l}\text { Three: short isoform ( } 42 \mathrm{kDa}) \text { and long isoform }(46 \mathrm{kDa}) \text { from } \\
\text { RcaA, third isoform }(42 \mathrm{kDa}) \text { from RcaB }\end{array}$ & (Rundle and Zielinski 1991) (Rollins et al. 2013) \\
\hline $\begin{array}{l}\text { Cotton (Gossypium } \\
\text { hirsutum) }\end{array}$ & $\begin{array}{l}\text { Two or } \\
\text { three }\end{array}$ & $\begin{array}{l}\text { Three: short isoform ( } 42-43 \mathrm{kDa}) \text {, long isoform }(46-47 \mathrm{kDa}) \\
\text { and a third isoform }(46 \mathrm{kDa})\end{array}$ & $\begin{array}{l}\text { (Law et al. 2001) (Salvucci et al. 2003) (Deridder and } \\
\text { Salvucci 2007) }\end{array}$ \\
\hline $\begin{array}{l}\text { Sweet potato } \\
\text { (Ipomoea batatas) }\end{array}$ & Two & $\begin{array}{l}\text { Two: short isoform RCA ( } 44 \mathrm{kDa} \text { ) and long isoform RCAI (47 } \\
\text { kDa) }\end{array}$ & (Xu et al. 2010) (Jiang et al. 2013) (Jiang et al. 2014) \\
\hline $\begin{array}{l}\text { Tobacco } \\
\text { (Nicotiana } \\
\text { tabacum) }\end{array}$ & Three & Three: short isoform $\beta$ & $\begin{array}{l}\text { (Qian and Rodermel 1993) (Carmo-Silva and Salvucci } \\
\text { 2013) (Carmo-Silva et al. 2015) }\end{array}$ \\
\hline $\begin{array}{l}\text { Soybean (Glycine } \\
\text { max) }\end{array}$ & Two & Two: short isoform $\beta$ and long isoform a & (Yin et al. 2010) \\
\hline
\end{tabular}


Shivhare and Mueller-Cajar 2017b). However, the Arabidopsis transformant rwt43 that contains only the Arabidopsis RCA isoform $\beta$, showed better sensitivity to ADP inhibition when tobacco RCA isoform $\beta$ gene was expressed, indicating that the function and regulation of RCA is species dependent (Carmo-Silva and Salvucci 2013). Perdomo et al. (2019) reported that RCA-2 $\beta$ in wheat shows ADP insensitivity during Rubisco activation when compared to the other two wheat RCA isoforms that were inhibited by increasing amounts of ADP. Changing two amino acid residues in RCA- $2 \beta$ to resemble RCA- $1 \beta$, caused the transformed RCA- $2 \beta$ to become ADP sensitive, suggesting the distinct properties of RCA isoforms, which directs them to respond to different physiological conditions. Moreover, work involving tobacco plants (Nicotiana tabacum L. cv Wisconsin 38) containing antisense DNA construct for RCA gene showed that reducing the total Rubisco activase content to less than $15 \%$ of the wild-type level led to a significant reduction in the Rubisco activation level during steadystate photosynthesis (Hammond et al. 1998). Additionally, the activase content became a limiting factor for Rubisco activation upon a rapid PFD increase. Thus, it could be possible that plants growing under continuous light and those growing under fluctuating irradiance may allocate relatively different amounts of proteins to Rubisco activase to maintain Rubisco activation. Recent studies report that in addition to redox regulation, posttranslational modifications such as acetylation (Hartl et al. 2017) and phosphorylation (Kim et al. 2019) are also involved in controlling RCA activity. Several basic leucine zipper (bZIP) transcription factors were identified in soybean where the regulation of $R C A$ gene expression appears to be trans-factor regulated (Zhang et al. 2016), opening doors to new areas of research to identify regulatory proteins in $R C A$ gene expression in soybean as well as in other crops.

Thus, the roles of RCA in plant productivity are manifold: maintaining Rubisco in its active state to safeguard continuous photosynthetic efficiency and conferring acclimation to moderate heat stress during grain filling stage (Wang et al. 2010; Shan et al. 2011; Yin et al. 2014; Scafaro et al. 2016). However, the high thermo-lability of RCA makes it an unattractive player in photosynthesis at beyond-optimal temperatures. Several studies pointed out that weakened RCA activity or its interaction with Rubisco at elevated temperatures $\left(>30^{\circ} \mathrm{C}\right)$ is one of the critical factors affecting photosynthetic rates under the present environmental conditions (Carmo-Silva et al. 2015; Busch and Sage 2017). Therefore, it would make sense to look into methods that would keep RCA active without itself being denatured and forming insoluble aggregates beyond the species-specific temperatures (Mueller-Cajar and Whitney 2008; Barta et al. 2010).

\section{Overexpression of $R C A$, a strategy with mixed results}

Extensive research has been carried out pertaining to rice and improving its productivity under environmental stress conditions due to the fact that rice is consumed as a staple food by half of the world population (Shivhare and Mueller-Cajar 2017a; Liu et al. 2020). Unlike in cotton or wheat, the rice RCA isoforms are encoded by a single gene through post-transcriptional splicing of premRNA, producing a $45 \mathrm{kDa}$ isoform $\alpha$ and a $41 \mathrm{kDa}$ isoform $\beta$, where the isoform $\alpha$ contains additional 33 amino acid residues at its $\mathrm{C}$-terminus and five amino acid substitution immediately before the 33 amino acid residues (Scafaro et al. 2016). The relationship between rice RCA/Rubisco and photosynthetic activity has been intensively studied since 1990s till today, and it was reported that while RCA is closely linked with the rate of photosynthesis in leaves throughout their development, the in vivo Rubisco activity and RCA content had an inverse relationship especially at young leaf stages (Fukayama et al. 1996; Fukayama et al. 2012; Fukayama et al. 2018). In their initial experiments carried out on the 10th leaf arising from the main stem of the rice variety Oryza sativa L. cv. Nipponbare under saturating $\mathrm{CO}_{2}$ and light conditions, Fukayama et al. (1996) showed that, although the photosynthetic rate had a linear relationship with the RCA content, the linear relationship between Rubisco content and the rate of photosynthesis plateaued with Rubisco content beyond $3 \mathrm{~g}^{-2}$ (Fukayama et al. 1996). Also, there was an exponential increase between Rubisco activity and the ratio of RCA/Rubisco. Further, while the maximum amount of Rubisco content in the leaf was seen by the third day of leaf emergence, the RCA content reached its highest amount by the 17th day, showing a greater accumulation of Rubisco in early leaf development compared to RCA. Yet, it was the RCA and photosynthetic rate, which had a linear relationship. Therefore, these findings led the authors to conclude that at the early leaf developmental stages, the rate of photosynthesis is not affected by Rubisco content higher than $3 \mathrm{~g}^{-2}$, but positively responds to RCA, and the Rubisco activity is restricted by the amount of RCA.

Jin et al. (2006) introduced an antisense $R C A$ into rice in which the RCA content was reduced to $30 \%$ of the wild-type level, and then investigated the localization of RCA as well as the alterations observed in Rubisco and RCA amount due to reduced RCA content. Key results from this work revealed that in rice, RCA was predominantly localized in the chloroplast stroma $(\sim 75 \%)$ with some in the thylakoid membranes $(\sim 25 \%)$, suggesting the species dependence of RCA localization as previously documented in Amaranthus tricolor (Hong et al. 2005) and spinach (Rokka et al. 2001). Compared to wild-type plants, there was a substantial increase in Rubisco 
amount in $R C A$ antisense plants with more than $96 \%$ of Rubisco located in the chloroplast stroma, indicating that the increase in Rubisco content could offset the RCA deficit. Despite the total Rubisco activity being lower in wild-type plants than in $R C A$ antisense plants, the net photosynthetic rate was significantly reduced in the $R C A$ antisense plants. It was speculated that even though the amount of Rubisco increases when RCA is reduced, this could be to compensate for the loss of $\mathrm{RCA}$, to have more Rubisco so the inactivation due to inhibitory sugar phosphate binding could be reduced although not completely outrun as shown by the decrease in the net photosynthetic rate.

In their more recent work using the Oryza sativa $\mathrm{L}$. cv. Nipponbare overexpressing either RCA small isoforms of barley (Hordeum vulgare L. cv. Kashima) or maize (Zea mays L. cv. Golden Cross Bantam), Fukayama et al. (2018) reported that when compared to the wild-type plants, transgenic lines overexpressing the barley $R C A$ small isoform had a higher activation of $\mathrm{Ru}$ bisco. Further, irrespective of the nitrogen supply, transgenic plants showed the lowest rate of photosynthesis, had significantly reduced amounts of Rubisco in mature leaves (9th leaf) as well as fully expanded leaves, showed no significant down-regulation of the Rubisco gene expression, and had no significant negative effects on plant biomass, growth rate or yield (Fukayama et al. 2012). Successive work in this area involving transgenic rice overexpressing maize $R C A$ (Ox-mRCA) and knockdown $r c a$ (KD-Rca) plants using antisense $R C A$ confirmed their previous findings of negative relationship existing between RCA and Rubisco. Transgenic lines overexpressing maize RCA (Ox-mRCA) had higher levels of RCA and thus, lower levels of Rubisco compared to transgenic lines overexpressing barley RCA. There was a significant increase in the Rubisco content in the $r c a$ knockdown lines and the opposite in the RCA-overexpression lines, as was indicated in previous work involving antisense $R C A$ (He et al. 1997; Jin et al. 2006). Also, this outcome was specific to Rubisco since there was no negative effect on enzymes in Calvin- Benson Cycle such as fructose1,6-bisphosphate aldolase, sedoheptulose-1,7bisphosphatase and phosphoribulokinase due to overexpression or antisense RCA (Fukayama et al. 2018). Despite observing an inverse relationship between RCA amount and Rubisco/total leaf protein in this study, the qRT-PCR results displayed significantly higher transcript levels of Rubisco small subunit-encoding genes (i.e. $O s R b c S 2-O s R b c S 5)$ and large subunit gene (OsRbcL), in both $R C A$ overexpression as well as KD-Rca plants when compared to wild-type plants. This suggested a possible post-transcriptional regulation or degradative mechanism of Rubisco being responsible for the discrepancies observed at protein level between RCA and Rubisco.
Additionally, during the polysome loading profile analysis where the distribution and sizes of the OsRbcS2, OsRbcL and Actin polysomes were analyzed, the results showed that OsRbcL translational activity was relatively higher in $R C A$-overexpressing lines compared to wildtype plants, while the OsRbcS2 transcript profile remained similar in all genotypes tested. Therefore, it was implied that the negative relationship observed between RCA and Rubisco protein levels was not due to alterations in translation of these Rubisco small and large subunits. Collectively, considering the overall results and the possible mechanisms of how RCA negatively affects Rubisco content, these results indicated that RCA may be negatively affecting plant Rubisco content possibly by interfering with the post-translational regulatory mechanisms of Rubisco biosynthesis, although this hypothesis requires further validation.

Several other research related to RCA and Rubisco content explains this negative relationship from a different standpoint, where it is suggested that rather than a trade-off, the change in Rubisco amount observed in either Rubisco small subunit or $R C A$ overexpression or antisense plants could come down to a matter of nitrogen allocation (Suganami et al. 2018; Suganami et al. 2020). As a result of overexpression of Rubisco small subunit genes, while the Rubisco content in the rice leaves increased in the transgenic plants, several other enzymes in Calvin Benson Cycle and RCA content decreased, despite this observation being somewhat conflicting to studies conducted in tobacco (Sage et al. 2008). The different results in tobacco and rice could be attributed to the difference in species since rice contains higher amount of Rubisco and a lesser repository of nitrogen, thereby having a higher impact in nitrogen partitioning (Suzuki et al. 2009; Suganami et al. 2018). Rice transgenic lines overexpressing different amounts of RCA driven by either Rubisco small subunit gene or $R C A$ gene promoters were grown under varying nitrogen concentrations (Suganami et al. 2020). It was seen that, till a $50 \%$ increase of RCA than wild-type, there was no reduction in the Rubisco content in the transgenic plants compared to wild-type regardless of the nitrogen levels, while the decrease in Rubisco that was observed in $R C A$ high-overexpressing lines could be offset with increasing nitrogen concentrations (Suganami et al. 2020). Thus, it was suggested that contradictory results obtained over several studies on the impact of RCA on Rubisco content (Mate et al. 1993; Eckardt et al. 1997; Yamori and Von Caemmerer 2009; Fukayama et al. 2018) is mainly due to dissimilarities in the nitrogen availability, since when $R C A$ antisense plants were grown in low nitrogen concentrations, the Rubisco content in rice plants increased significantly (Suganami et al. 2020). Overexpressing both Rubisco subunit genes and $R C A$ genes at 
moderate levels might prove to be a practical approach in improving photosynthesis, leading to better yield. In fact, several recent studies have shown that overexpression of both Rubisco small subunit (RBCS) and Rubisco activase $(R C A)$ genes contributes toward enhancing photosynthesis in plants. For instance, a study where wild-type rice (Oryza sativa) along with rice Rubisco small subunit 2 (RBCS2) overexpressing (RBCS-ox), rice RCA small isoform overexpressing (RCA-ox), and Rubisco/RCA co-overexpressing (RBCS-RCA-ox) plants were used, showed that the $\mathrm{CO}_{2}$ assimilation rates at moderately high temperatures $\left(32-36^{\circ} \mathrm{C}\right)$ were highest in RBCS-RCA-ox plants (Suganami et al. 2021). Although the Rubisco amounts were slightly less in RCAox plants compared to other genotypes tested, the $\mathrm{Ru}-$ bisco activation state was higher in these plants at elevated temperatures, while all other plants tested showed a decrease in activation state of Rubisco as the temperatures were increased. Moreover, work carried out by $\mathrm{Qu}$ et al. (2021) using three rice lines wild-type, Rubisco activase overexpressing (oxRCA), and Rubisco/Rubisco activase co-overexpressing (oxRCA-RBCS) plants demonstrated that rate of $\mathrm{CO}_{2}$ assimilation (A) at $40{ }^{\circ} \mathrm{C}$ was $15 \%$ and $20 \%$ higher in oxRCA and oxRCA-RBCS plants, respectively, when compared to wild-type rice plants. Additionally, while there was no significant difference in the dry biomass between wild-type and oxRCA plants at $40^{\circ} \mathrm{C}$, the oxRCA-RBCS plants had a $26 \%$ higher dry weight compared to wild-type plants. Taken together, these findings provide evidence that co-overexpressing both Rubisco and RCA might prove to be a promising approach to improve photosynthesis and yield under elevated temperatures.

\section{Improving thermo-tolerance of RCA: initial work}

Several early studies reported positive results through improving the thermo-tolerance of RCA, leading to enhanced photosynthesis at elevated temperatures. In one of these studies the thermo-stable RCA variants of Arabidopsis thaliana were generated through gene shuffling by isolating, fragmenting, and reassembling the RCA short isoform (RCA1), where these variants as well as wild-type RCA1 were expressed in the Arabidopsis $R C A$ deletion mutant plant $(\Delta r c a)$ that lacks $R C A$ DNA sequence from exon 5 to 7 (Kurek et al. 2007). This was followed by exposing the transgenic lines to a continuously elevated temperature of $26^{\circ} \mathrm{C}$ or $30^{\circ} \mathrm{C}$ for $4 \mathrm{~h}$ a day (Kurek et al. 2007). Compared to the wild-type RCA1, the RCA variants maintained a higher Rubisco activity at elevated temperatures, indicating that RCA variants responded better than the wild-type RCA1 at moderate heat stress conditions. The homozygous $\Delta r c a$ plants showed distinct physiological and phenotypic characteristics compared to the wild-type plants, such as low photosynthetic rates at ambient $\mathrm{CO}_{2}$ concentration, lower leaf area and stunted growth. More importantly, a significantly higher number of siliques and higher seed weight were observed in the $\Delta r c a / R C A 1$ variant transgenic lines when compared to the wild-type and $\Delta r c a /$ $R C A 1$ heterozygous lines, when these plants were continuously exposed to $26^{\circ} \mathrm{C}$ or $30^{\circ} \mathrm{C}$ for $4 \mathrm{~h}$ a day. This research indicates the essential role played by RCA in photosynthesis and how improving its thermo-stability can lead to better plant growth and higher seed yield under moderate heat stress conditions.

Shortly after using the gene shuffling method, another approach was attempted in achieving the goal of enhancing RCA thermo-stability, i.e., producing a stable chimeric RCA to improve heat tolerance. Previous work have shown that RCA belonging to plant species growing in different temperature conditions have distinct cut off temperature optima for their activities (Salvucci et al. 2001; Salvucci and Crafts-Brandner 2004b). However, incorporation of a thermo-stable RCA in a different host plant had previously resulted in incompatibility due to species specificity, leading to a failure in activating $\mathrm{Ru}$ bisco in the transgenic plants ( $\mathrm{Li}$ et al. 2005). Kumar et al. (2009) created a chimeric RCA (i.e. Tob-Arab) where the Rubisco recognition domain of tobacco RCA was replaced with the one from Arabidopsis RCA, which was expressed in the Arabidopsis $r c a$ mutant deficient of wild-type RCA (Kumar et al. 2009). In vitro studies showed that after $20 \mathrm{~min}$ at $37^{\circ} \mathrm{C}$, Tob-Arab retained $83 \%$ of its initial activity at $25^{\circ} \mathrm{C}$, compared to the wildtype Arabidopsis and tobacco that retained 33\% and 67\% of their initial activities, respectively (Kumar et al. 2009). Similar trend was observed at $40{ }^{\circ} \mathrm{C}$ for $20 \mathrm{~min}$, where wild-type Arabidopsis RCA showed minimal activity, while tobacco and Tob-Arab preserved $40 \%$ and $50 \%$ of their initial activities, respectively. Further, after 6 weeks of growth in continuous temperature at $27^{\circ} \mathrm{C}$, transgenic plants expressing the chimeric RCA displayed greater biomass than wild-type plants, while the photosynthetic rate after a brief exposure to $38^{\circ} \mathrm{C}$, was $38-46 \%$ greater than that of wild-type plants. As a result of higher rates of photosynthesis and improved biomass, the transgenic lines produced about four times more total seed weight per plant than wild-type plants, as well as higher seed viability. These findings further strengthened the notion of improved plant productivity due to better thermotolerance of RCA.

In addition to these research pertaining to RCA and its enhanced thermo-tolerance, numerous studies in the past decades provided us with better insight into RCA through identification and characterization of its subunits and isoforms as well as molecular methods that could be adopted to improve the thermo-tolerance of RCA to increase plant productivity. As of now, the 
crystal structures of RCA from three different plant species, tobacco (Stotz et al. 2011), desert shrub creosote (Henderson et al. 2011), and Arabidopsis (Hasse et al. 2015), have been elucidated. However, a major drawback that hampers the study of RCA proteins is the difficulty in isolating this enzyme in its native form with the complete amino acid sequence due to its conformational flexibility and instability, leading to the formation of large aggregates during protein purification (Hasse et al. 2015). Thus, only partial amino acid sequences or the truncated forms of RCA were analyzed in the study of its crystal structure and in predicting the exact mechanism of Rubisco-RCA interaction. However, a completely functional RCA was recently engineered using the photosynthetic proteobacterium Rhodobacter sphaeroides, which allowed the study of the protein-protein interactions between Rubisco and RCA under normal conditions (Bhat et al. 2017a). This has provided a better insight into how the Rubisco catalytic core and its vicinity interacts with or binds to RCA in Rubisco activation, facilitating RCA to open the Rubisco active site. Similar findings have been reported where it is shown that RCA top surface acts as the Rubisco interacting face, with the RCA $\alpha 4-\beta 4$ loop contributing towards the RCA-Rubisco interaction (Shivhare and Mueller-Cajar 2017a). This work has broadened the understanding of RCA function in Rubisco activation, which is invaluable in unraveling the detailed mechanism on the conformational changes taking place in Rubisco activation, while also helping to explore the structural and biochemical tweaks required to improve Rubisco carboxylation as well as RCA thermo-tolerance in crop plants.

\section{RCA and heat acclimation}

When plants are exposed to prolonged and gradual increase of a particular stress such as heat, low temperature or water deficit, certain physiological and biochemical changes develop in plants to tolerate these stresses to a certain extent, so that plants could perform better under a new environmental condition, which is coarsely described as acclimation (Anjum 2015; Sándor et al. 2018). Therefore, many studies have explored RCA's capacity in heat acclimation, due to its thermolability. When creeping bentgrass (Agrostis stolonifera L.), a type of cool-season perennial grass, was exposed to either gradual temperature increase from $20,25,30,35$ to $40{ }^{\circ} \mathrm{C}$, or immediate increase from 20 to $40{ }^{\circ} \mathrm{C}$, the heat acclimated plants displayed significantly better photosynthetic rates, higher Rubisco activity and activase activities (Liu and Huang 2008). Hence, unlike in a rapid increase in the environmental temperature where RCA tends to undergo thermal denaturation and form insoluble aggregates, when plants are exposed to a slow incremental temperature, it enables RCA to get acclimated to the increasing heat stress (Salvucci and CraftsBrandner 2004a; Salvucci 2008; Deridder et al. 2012). RCA undergoes heat acclimation using many strategies including enzyme stabilization, producing heat-stable or heat-inducible isoforms, or increasing or decreasing the isoform expression levels depending on their sensitivity to heat stress, resulting in a RCA isoform ratio different to that of under normal conditions (Portis 2003; Kurek et al. 2007; Salvucci 2008). A study demonstrating the role of RCA in keeping Rubisco active was conducted when tobacco plants transformed with the $R C A$ antisense construct and wild-type tobacco plants were exposed to heat stress, where the photosynthetic rates declined above $30^{\circ} \mathrm{C}$ and $36^{\circ} \mathrm{C}$, respectively, while wildtype plants showed a significantly higher recovery rate in photosynthesis upon decreasing the temperature compared to the antisense plants (Sharkey et al. 2001).

Within this frame, many research have focused on the relationship of RCA isoforms and regulatory elements under heat stress, which underscores the importance of improving the thermo-tolerance of plants through acclimation and how RCA could contribute towards increased productivity under heat stress conditions. For instance, in many crops including wheat, cotton and maize, a heat inducible RCA isoform was detected along with the isoforms that are constitutively expressed (Deridder and Salvucci 2007). Earlier work on cotton reported a new $\mathrm{RCA}$ isoform of $46 \mathrm{kDa}$ in addition to the constitutively expressed 47 and $43 \mathrm{kDa}$ polypeptides, being synthesized upon exposure to $41 / 37^{\circ} \mathrm{C}$, which was degraded after removing the heat stress (Law et al. 2001). Such emergence of new RCA isoforms that are not constitutively expressed were found in several monocot crops including maize (Sanchez De Jimenez et al. 1995) and wheat (Law and Crafts-Brandner 2001). The third RCA isoform in cotton upon exposure to heat stress declined drastically although recovered during prolonged heat stress, and the longer

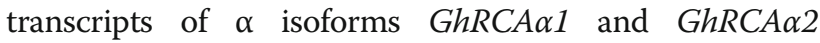
showed five different length variations at their 3 ' untranslated regions ( $3^{\prime}$-UTRs), specifically lacking the putative instability sequences, indicating the possibility of maintaining the RCA transcript stability during extended heat stress, which could be attributed to a post-transcriptional mechanism contributing to photosynthesis acclimatization (Deridder and Salvucci 2007). Work on Arabidopsis RCA showed that among the three isoforms under heat stress conditions, the abundance of AtRCA $\beta 2$ isoform tripled from $4 \%$ to $12 \%$ of the total $R C A$ pool, leading to an overall reduction of the Arabidopsis $R C A$ average 3 '-UTR length since AtRCA $\beta 2$ contains the shortest invariable 3'UTR length among isoforms, supporting a previous idea that shorter 3'-UTR length confers better RCA thermostability (Deridder et al. 2012). Further, qPCR analysis of the isoforms showed that the AtRCA $\beta 2$ transcript level 
remained stable throughout heat stress treatment, while the transcript levels of $A t R C A \alpha$ and $A t R C A \beta$ were relatively less stable, implying the importance of $A t R C A \beta 2$ in maintaining steady-state $R C A$ transcript levels under heat stress conditions.

Previous work on wheat RCA under heat stress condition indicated an increase in one of the constitutive RCA isoform of $42 \mathrm{kDa}$ with the larger isoform of $46 \mathrm{kDa}$ showing no increase, while a putative $41 \mathrm{kDa}$ isoform transcript was induced upon exposure to heat stress (Law and Crafts-Brandner 2001). In contrast, more recent studies showed that, when compared to the $42 \mathrm{kDa}$ isoform, a higher abundance of the $45-46 \mathrm{kDa}$ isoform was observed when wheat plants were exposed to heat stress conditions at $36 / 30^{\circ} \mathrm{C}$ (day/night) for 7 days, where a positive association between the higher transcript level of this wheat isoform and plant biomass and productivity was also reported (Ristic et al. 2009; Kumar et al. 2016). However, when barley was exposed to heat stress at $36^{\circ} \mathrm{C}$, there was a significant upregulation of the Rubisco activase B transcript while the Rubisco activase A transcript was downregulated (Rollins et al. 2013). Additionally, transcriptome analysis using Next Generation Sequencing was performed on thermotolerant and thermo-susceptible wheat varieties under control and heat stress conditions, where eight putative $R C A$ transcripts were identified and a novel gene TaRCA1 was cloned (Kumar et al. 2016). This study confirmed the findings associated with the previous work and transcriptome analyses involving wheat, where the thermo-tolerant varieties showed higher RCA expression, greater total antioxidant capacity, increased Rubisco activity and an increased RCA activity under heat stress conditions (Xue et al. 2015; Kumar et al. 2017; Kumar et al. 2019). The findings also pointed out that at different developmental stages, the expression patterns of $R C A$ genes differed among the wheat varieties, influencing the accumulation of Rubisco, which mirrored the $R C A$ transcript dynamics, showing the importance and potential of TaRCA1 in regulating Rubisco activity and how it could be used for the benefit of enhancing thermo-tolerance in crops. This also shows how the thermo-stability of RCA depends on the species and the climatic and environmental conditions in which it has evolved.

A study on red maple using heat sensitive "Northwood" and heat insensitive "Florida flame" showed similar results, where the $\mathrm{CO}_{2}$ assimilation rates dropped at temperatures above $33^{\circ} \mathrm{C}$ in the heat sensitive "Northwood" with an increase observed in small RCA isoform, while it was beyond $40^{\circ} \mathrm{C}$ for the heat insensitive "Florida flame" with both isoforms showing a modest increase, implying that though not solely responsible for the thermo-tolerance displayed, RCA could contribute substantially to the heat acclimation (Weston et al. 2007). It was found that within the same species, the amino acid sequences of RCA and Rubisco could vary significantly, giving rise to thermo-tolerant and thermosusceptible varieties (Kumar et al. 2019). As shown in the transcriptome data, within the same crop wheat, there are thermo-tolerant and thermo-susceptible varieties that display varying degrees of RCA activity under heat stress conditions. Recently, a conserved sequence in RCA was identified in a thermo-tolerant wheat species that confers heat stability (Scafaro et al. 2019). The response of the three wheat RCA isoforms, TaRCA1- $\beta$, TaRCA2- $\alpha$, and TaRCA2- $\beta$, to heat stress was first analyzed through expression profiling, followed by linking the association between regulation of these isoforms and RCA thermo-stability during heat stress treatment. It was observed that, similar to cotton and maize, expression of more thermally stable RCA isoforms is induced in response to heat stress in wheat, in particular the TaRCA1- $\beta$ gene irrespective of the cultivar. Additionally, the amino acid sequence from the thermally susceptible TaRCA2- $\beta$ was compared with TaRCA1- $\beta$, the rice RCA isoform OsRCA- $\beta$, and cold- and warm-adapted species' RCA consensus sequences using sequence alignment and protein structural modeling. There were 11,8 and 3 amino acid substitutions made in the wild-type TaRCA2- $\beta$ amino acid sequence, based on the differences identified exclusively with TaRCA1- $\beta$, OsRCA- $\beta$, TaRCA2- $\beta$, and/or cold-adapted RCA. These three types of amino acid variants were named as TaRCA2- $\beta-11 \mathrm{AA}$, TaRCA2- $\beta-8 A A$ and TaRCA2- $\beta$-3AA. The subsequent experiments showed that all three TaRCA2- $\beta$ variants had higher thermo-stability than did wild-type TaRCA2$\beta$ isoform, where TaRCA2- $\beta$-11AA displayed the greatest thermo-stability at temperatures of $41.5^{\circ} \mathrm{C}$ to $42.4^{\circ} \mathrm{C}$, which was $7{ }^{\circ} \mathrm{C}$ more than wild-type TaRCA2- $\beta$. Further, the kinetic efficiency of the TaRCA2- $\beta$ mutants did not appear to be affected due to the amino acid alterations, showing great potential of utilizing this technique to improve the RCA thermo-tolerance without compromising the enzyme efficiency. A recent study on wheat showed how a single point mutation created in RCA2 $\beta$ at position 159 to replace methionine with isoleucine, conferred enhanced thermo-tolerance of wheat RCA activity while also sustaining the Rubisco activation state (Degen et al. 2020). Likewise, biochemical studies on agave and rice $\mathrm{RCA}$ isoforms have revealed that due to differences in the amino acid sequences at the $\mathrm{N}$-terminus of agave $\mathrm{RCA}$, it is $10^{\circ} \mathrm{C}$ more thermo-stable than rice $\mathrm{RCA}$, while also maintaining a relatively higher ATPase and activase activity at low temperatures such as $15^{\circ} \mathrm{C}$ (Shivhare and Mueller-Cajar 2017a). Thus, either overexpression of the thermo-stable RCA isoforms or editing the thermo-labile isoforms to improve their thermo-stability 
could prove to be practical approaches in achieving thermo-tolerance of plants.

However, a broader knowledge of RCA regulation related to its subunit composition and amount is necessary in order to effectively improve its thermo-tolerance and reap its benefits in agriculture. Regulation of RCA expression in plants does not always share the same mechanism, for example, transcriptional mechanisms leading to transcript abundance changes were observed in cotton, whereas translational mechanisms were apparent in wheat (Law and Crafts-Brandner 2001; Deridder and Salvucci 2007). In maize, the amount of RCA polypeptide and chaperon activity are regulated post-translationally with developmental and environmental cues playing a significant role (Vargas-Suárez et al. 2004). Moreover, some early research also showed contradicting results with different isoforms having a higher abundance under heat stress such as in wheat, which could be due to the discrepancies existing among many factors including experimental conditions, plant age or developmental stages (Law and Crafts-Brandner 2001; Ristic et al. 2009). In different crops, depending on the type of stress imposed, the abundance of specific RCA isoform varies (Perdomo et al. 2017), which further adds to the complexity of RCA expression and regulation, highlighting the need to understand RCA, Rubisco, and their interaction at elevated temperatures.

Rice RCA isoforms were shown to be unequally localized in different parts of the leaves, leading to distinct photosynthetic rates and participating differently in photosynthetic heat acclimation. The work by Wang et al. (2009) using Oryza sativa L. 'Zhenong 952' reported that under control conditions, the larger RCA isoform $\left(\mathrm{RCA}_{\mathrm{L}}\right)$ /smaller isoform $\left(\mathrm{RCA}_{\mathrm{S}}\right)$ ratio in fully expanded leaves was 1:5, which is likely due to transcript levels of the two isoforms, corroborating with their subsequent work on investigating the functions of the different rice RCA isoforms (Wang et al. 2010). Although there were differences in the isoform protein levels in leaves at varying developmental stages, the mRNA content corresponding to these isoforms showed no significant difference, pointing toward a post-translational regulation of RCA isoforms rather than transcriptional (Wang et al. 2009). Their initial work showed that the leaves with the highest photosynthetic rates at $35^{\circ} \mathrm{C}$ had a higher $R C A_{L} / R C A_{S}$ ratio, while the oldest leaf (leaf 2) with the lowest photosynthetic rate had a lower $\mathrm{RCA}_{\mathrm{L}} /$ $\mathrm{RCA}_{S}$ ratio (Wang et al. 2009). They also demonstrated that upon exposure to a heat stress cycle of $40 / 30^{\circ} \mathrm{C}$, the alternative splicing of RCA pre-mRNA produced more $R C A_{L}$, resulting in a significantly higher amount of $R C A_{L}$ vs $R C A_{S}$ during heat stress treatment. Once the heat stress was removed, the $\mathrm{RCA}_{\mathrm{L}}$ and $\mathrm{RCA}_{\mathrm{S}}$ levels returned to the levels detected under control conditions again (Wang et al. 2010). Additionally, the transgenic rice overexpressing $R C A_{L}$ had better photosynthetic rates during heat stress treatment compared to wild-type and $R C A_{s-}$ overexpression lines. The latter showed a better photosynthetic rate and initial Rubisco activity under control conditions, as well as a higher amount of RCA isoform in rice leaves under controlled condition, implying the different roles played by the two RCA isoforms under different conditions, which could be applicable in generating thermo-tolerant crop varieties.

In addition to more thermo-stable isoforms, in recent years several rice varieties have been identified that displayed better heat tolerance when compared to its most common species Oryza sativa. Thus, when the commercial O. sativa $(O s)$ and two wild rice species Oryza meridionalis $\mathrm{Ng}$. (Om) and Oryza australiensis Domin (Oa) were exposed to heat stress conditions (i.e. $45 / 28^{\circ} \mathrm{C}$ ), $\mathrm{Oa}$ plants showed the greatest leaf elongation rates, the highest Rubisco activation state during heat stress treatment and no significant decrease in the net photosynthesis $\left(P_{n}\right)$, while $P_{n}$ was reduced by roughly $40 \%$ and $27 \%$ under control conditions in $\mathrm{Os}$ and $\mathrm{Om}$, respectively (Scafaro et al. 2016). Further, the purified extracts of RCA isoform $\beta$ of $\mathrm{Oa}$ remained active at $42^{\circ} \mathrm{C}$, while the RCA from $O s$ was inhibited at temperatures beyond $34^{\circ} \mathrm{C}$. Probing into the DNA and amino acid sequences of the RCA in Os and $\mathrm{Oa}$ revealed that, the differences observed between the two were primarily located toward the $\mathrm{N}$ - and C-termini, which could explain why the RCA from $\mathrm{Oa}$ appeared to be more thermo-stable. The most unstable flexible regions of the RCA are the $\mathrm{C}$ - and $\mathrm{N}$ terminal domains that are critical in Rubisco recognition and binding (Li et al. 2005; Stotz et al. 2011; Parry et al. 2013), hence the differences existing in the RCA from $O a$ in this region compared to that of Os likely lead to better stability and reduced structural flexibility, thereby causing it to be more thermo-stable while also decreasing the species specific activity, although the latter was compensated by the higher ratio of RCA to Rubisco observed in $\mathrm{Oa}$ (Scafaro et al. 2016). Research on agave RCA structure also showed that when compared to the RCAs of tobacco and Arabidopsis, agave RCA contains an additional 11 amino acid residues in a loop that connects the alpha helix 4 and beta strand 4 , which aids in Rubisco interaction. This leads to less structural flexibility, thereby conferring a higher thermo-stability to agave RCA (Shivhare and Mueller-Cajar 2017a). An extension to the rice RCA work was carried out where plant growth, photosynthesis and yield were evaluated in transgenic $O$. sativa lines overexpressing different levels of RCA isoforms of $\mathrm{Oa}$ (e.g. 9-19\% of the total plant RCA content) under heat stress conditions $\left(45 / 22{ }^{\circ} \mathrm{C}\right)$ (Scafaro et al. 2018). Results show that while plant height and biomass between the transgenic and wild- 
type plants showed no major difference, the number of seeds at maturity in the transgenic plants containing $19 \%$ of $O a$ 's RCA in the total RCA pool were around 2.5 fold higher than that of wild-type plants under heat stress conditions, indicating that the transgenic plants benefited from the improved Rubisco activation kinetics and non-steady-state photosynthesis under heat stress due to overexpression of a thermo-tolerant RCA.

\section{Overexpression of RCA for enhanced thermo- tolerance: recent progress}

In recent years, research was focused on overexpressing different $R C A \mathrm{~s}$ in a variety of plant species to ascertain their ability to enhance thermo-tolerance, thereby improving photosynthetic rates and plant productivity under elevated temperatures. Compared to the wild-type plants, $R C A$-overexpressing cucumber displayed significant improved thermo-tolerance at $40{ }^{\circ} \mathrm{C}$, with higher mRNA abundance of Rubisco subunit genes, more $\mathrm{Ru}$ bisco enzyme, and higher RCA activities, leading to better photosynthetic rates ( $\mathrm{Bi}$ et al. 2016). To test if overexpressing a naturally more thermo-tolerant RCA in transgenic plants could improve photosynthesis, thereby leading to higher seed yield under heat stress conditions, we overexpressed the $R C A$ isoform $\alpha$ gene, $L t R C A$, from a desert shrub commonly growing in Arizona and Mexico (i.e. Larrea tridentate) in Arabidopsis and analyzed how LtRCA-overexpressing Arabidopsis plants would perform under heat stress conditions. The rationale behind this experiment was based on the fact that Larrea tridentate has adapted to the hot desert in America's Southwest, and it frequently experiences temperatures above $40-45^{\circ} \mathrm{C}$ in the summer, therefore if the RCA from Larrea tridentate would interact with the $\mathrm{Ru}$ bisco in Arabidopsis, then it might improve the performance of Arabidopsis' Rubisco under heat stress conditions. Indeed, we found that $L t R C A$-overexpressing Arabidopsis plants performed much better than wildtype plants under the heat stress condition of $42^{\circ} \mathrm{C}$ for $5 \mathrm{~h}$ and $22^{\circ} \mathrm{C}$ for $19 \mathrm{~h}$ per day (Fig. 2b). It appears that $L t R C A$-overexpression only affects the heat tolerance, which was expected as RCA only affects Rubisco's activity (i.e. $\mathrm{CO}_{2}$ fixation), not other cellular metabolic functions.

In nature, abiotic stresses rarely come alone, instead they often come in various combinations, especially for drought and heat stresses. Therefore it would make more sense if we make plants more drought and heat tolerant
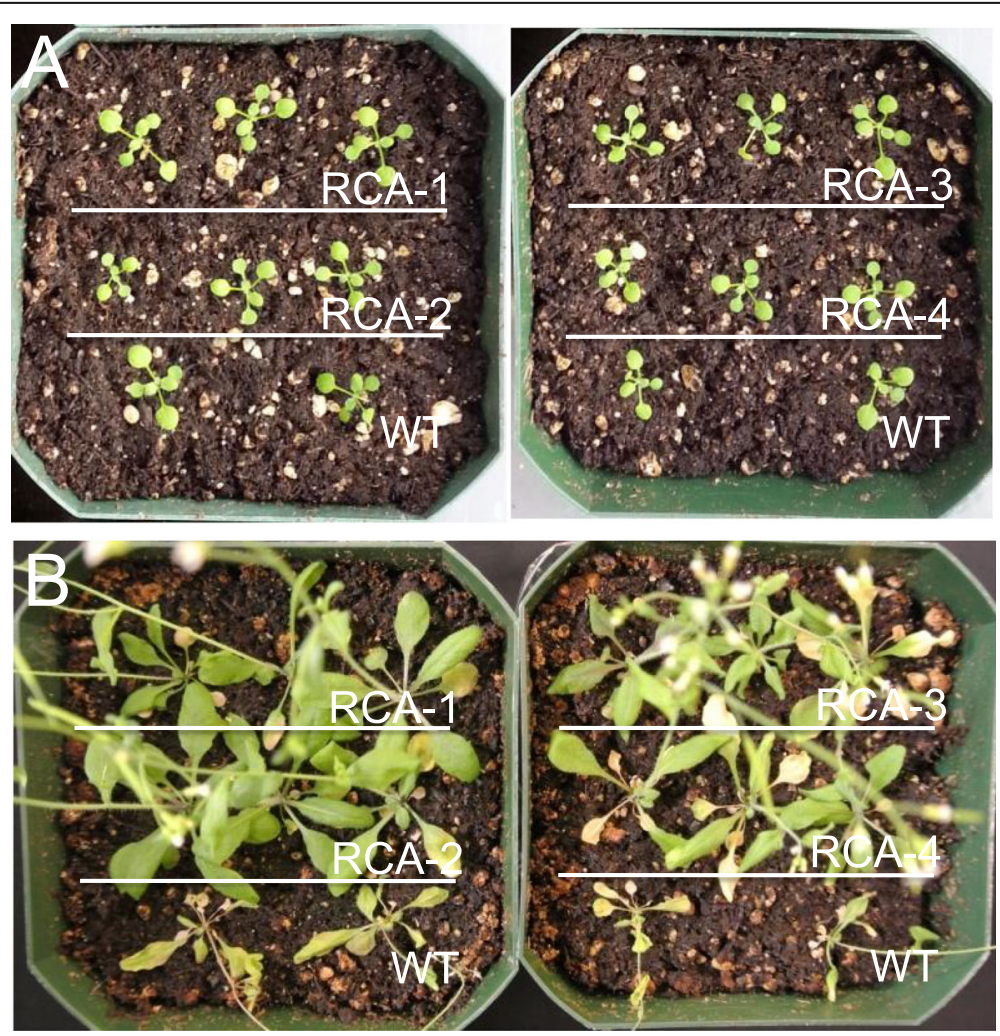

Fig. 2 Phenotypes of $L t R C A$-overexpressing plants under heat stress conditions. a Arabidopsis plants before heat stress treatment. b Arabidopsis plants after heat stress treatment. Arabidopsis plants were grown under normal growth condition $\left(22^{\circ} \mathrm{C}\right.$ continuously) for 3 weeks (photo A was taken at day 20), then moved to a heat chamber $\left(42^{\circ} \mathrm{C}\right.$ for $5 \mathrm{~h}$ and $22^{\circ} \mathrm{C}$ for $19 \mathrm{~h}$ each day) until the end of the experiment (photo B was taken at day 40 after the start of heat treatment). WT, wild-type plants; RCA-1 to RCA-4, four independent LtRCA-overexpressing plants 
simultaneously, which could dramatically increase yield for crops grown in arid and semi-arid regions of the world. We then tested the idea of co-overexpression of $L t R C A$ with another gene that confers increased droughtand salt-tolerance in order to obtain transgenic plants that are significantly more heat-, drought-, and salt-tolerant. For this purpose, we stacked the LtRCA gene with the $A V P 1$ gene from Arabidopsis and introduced these two genes into Arabidopsis. Previous work indicated that overexpression of $A V P 1$ in transgenic plants could improve both drought and salt tolerance (Gaxiola et al. 2001; Pasapula et al. 2011), consequently we expected that $A V P 1 /$ LtRCA co-overexpressing plants would be more tolerant under heat, drought, salt, as well as under multiple stress conditions. Indeed, this was exactly what we observed. For example, when wild-type and AVP1/LtRCA cooverexpressing plants were exposed to heat stress conditions $\left(37 / 22^{\circ} \mathrm{C}\right.$ for $5 / 19 \mathrm{~h}$ per day) for 2 months, $A V P 1 /$ $L t R C A$ co-overexpressing plants were indeed more tolerant to heat, drought, and salt stress separately as well as in all combinations (Wijewardene et al. 2020). More importantly, $A V P 1 / L t R C A$ co-overexpressing plants had higher plant biomass and significantly higher seed yield under combined heat and drought stress conditions than AVP1overexpressing and $L t R C A$-overexpressing plants, indicating that co-overexpression of $A V P 1$ and LtRCA in Arabidopsis appears to have a synergism that makes transgenic plants performing better than overexpression of these two genes separately. Our research showed a great potential of improving plant productivity by using a thermo-stable RCA to maintain photosynthetic rate at elevated temperatures, which could translate into higher crop yield when climate change brings us a more serious problem in the future. Our proof-of-concept work in Arabidopsis has been confirmed recently as our preliminary work with transgenic cotton indicate that AVP1/LtRCA cooverexpressing cotton plants perform much better under combined heat and drought stress conditions in both greenhouse and field trials than wild-type and AVP1-overexpressing cotton plants, with significantly improved fiber yields under all stress conditions tested (unpublished data).

\section{Future of RCA}

Several fundamental details remain to be explicated on the interaction between RCA and Rubisco including the role of ATP hydrolysis during Rubisco activation, the exact conformational changes during Rubisco activation and inactivation, and factors contributing to the inactivation and activation of Rubisco by RCA. Additionally, the regulation of RCA requires further exploration to better understand its catalytic activity and how it associates with the chloroplast thylakoid membranes. RCA abundance shifts between thylakoid membranes and chloroplast stroma during exposure to heat stress (Jin et al. 2006), implying that changes take place in the binding capacity of RCA to membranes under heat stress conditions. Several mechanisms on the regulation of RCA activity have been proposed including phosphorylation, acetylation and redox balance (Kim et al. 2019). However, deciphering the factors involved in driving these regulatory activities and their interaction in this complex network, requires further exploration. With the identification and characterization of RCA-like proteins in lower organisms such as cyanobacteria might shed some light in our understanding of the importance of activase and its evolution towards its role in Rubisco activation (Flecken et al. 2020). Further, in evaluating the effects of overexpressing $R C A$, the developmental stage of leaves as well as the ratio of Rubisco vs RCA appear to be important in achieving the optimal photosynthetic efficiency. It is well established that Rubisco inactivation is a primary reason for the reduced net photosynthesis in plants, which could be due to limitation of RCA as well as RCA-independent activities under heat stress conditions (Kim and Portis Jr 2005). In this context, a great emphasis is placed on research related to the $3^{\prime}$-UTR regions of $R C A$ transcripts as a major determinant in conferring thermo-tolerance (Deridder and Salvucci 2007; Deridder et al. 2012). Moreover, an acidic minipeptide designed to resemble the conserved C-terminal extension of RCA was fused to several heat labile proteins such as cytosolic ascorbate peroxidase and TATA-box binding protein, and these fusion proteins were introduced into Escherichia coli and Saccharomyces cerevisiae cells to evaluate the thermostability of these recombinant proteins (Zhang et al. 2015). The positive results of improved thermo-stability in these fusion proteins suggest that this strategy in increasing RCA thermo-tolerance might improve crop performance at elevated temperatures.

The increased Rubisco inactivation under heat stress as a consequence of reduced RCA activity should be well examined. For instance, this could be a result of a protective mechanism against photorespiratory metabolites that prevent further damages to plant cells under heat stress (Sharkey 2005; Weston et al. 2007). If a single amino acid substitution could improve the thermotolerance of RCA, the question arises why this beneficial feature did not take place under natural selection in nature. At elevated temperatures, the oxygenase activity of Rubisco also increases, leading to carbon loss and increased energy demands (Mueller-Cajar and Whitney 2008). On the other hand, reducing the Rubisco activity to minimize photorespiration even under moderate heat stress could negatively affect plant growth and survival. However, the initial work by Kumar et al. (2009) and Kurek et al. (2007) clearly indicated that improving the thermo-tolerance of RCA could be achieved, while 
maintaining high Rubisco activity and net photosynthesis, thereby leading to improved plant growth and development under moderate heat stress conditions.

Moreover, the negative effect caused by increasing RCA content such as decreased amount of Rubisco, leading to reduced photosynthesis and biomass (Fukayama et al. 2012; Suganami et al. 2020), still remains a topic of debate that requires further evidence. Research has shown how a diverse collection of factors apart from RCA markedly affect Rubisco content in leaves, including atmospheric $\mathrm{CO}_{2}$ level, plant hormones such as ABA, removal of fruit altering the sink-capacity, and rain (Crafts-Brandner et al. 1991; Fukayama et al. 2010; Fukayama et al. 2018). Hence, if the photosynthetic capacity needs to be improved and the yield increased, the underlying complex mechanism regulating Rubisco and RCA contents require to be carefully assessed. Experiments would need to be carried out under heat stress conditions as well as in different crops before a clear conclusion can be drawn.

Species specificity is also a factor that should be considered when overexpressing a foreign $R C A$ gene. Although numerous reports showed that RCA and Rubisco from two different plant species could interact with each other (Fukayama et al. 2012; Yamori et al. 2012; Wijewardene et al. 2020), incompatibility could occur with certain species, which could pose a serious problem. For instance, an earlier work showed the specificity of RCARubisco interaction between Solanaceae plants like tobacco and non-Solanaceae plants such as spinach, making RCA incapable of activating Rubisco (Wang et al. 1992). This is primarily due to the differences in amino acid residues in the interaction domains of RCA and $\mathrm{Ru}-$ bisco, which are essential for the correct protein-protein interaction (Ott et al. 2000; Kumar et al. 2009), resulting in less effective enzyme-substrate association ( $\mathrm{Li}$ et al. 2005; Hasse et al. 2015). The coevolving mechanism of RCA and its Rubisco leads to a highly species-specific recognition between RCA and Rubisco (Bhat et al. 2017a; Nagarajan and Gill 2018). To overcome such obstacles, in addition to the studies related to protein structure and biochemical characteristics, further research should be carried out to explore the existence of thermo-tolerant varieties of the same plant species where thermo-tolerant RCA varieties could be introduced to thermo-susceptible cultivars. Research related to wheat (Scafaro et al. 2019) and rice (Scafaro et al. 2016; Scafaro et al. 2018) have shown the presence of several wild species thriving in higher environmental temperatures, whose RCA could be introduced into the commercial varieties to enhance RCA's thermo-stability in wheat and rice. At certain times, a lower catalytic activity of RCA is observed among the thermo-tolerant species despite their thermal stability, however, this drawback appears to be compensated by the higher RCA/Rubisco ratio in leaves (Scafaro et al. 2016). Careful assessment of thermostable as well as sensitive RCA and their regulatory sequences such as promoter regions may provide useful insights into this avenue to better understand, manipulate, and create RCA catering to the prevailing agricultural requirements.

Countless studies demonstrated the important role played by RCA and how it could be utilized to effectively improve the thermo-tolerance of plants, especially agriculturally important crops. In addition to heat tolerance, several studies reported the importance of RCA in conferring tolerance to low temperatures and low light (Jurczyk et al. 2015b; Bi et al. 2017), suggesting that there is much to be learned about this molecular chaperone. Apart from genetic manipulation, numerous methods of increasing RCA content in plants have been tried, including application of chemicals and creating mini peptides. For example, upon exogenous application of sodium bicarbonate on rice leaves, it was observed that RCA transcript and protein levels were significantly up-regulated and biochemical parameters such as $\mathrm{RuBP}$ regeneration, net photosynthetic rate, and initial Rubisco activity were also enhanced (Chen et al. 2014). Likewise, pretreatment of wheat seedlings with 2,4-epibrassinolide (a type of the steroid hormone brassinosteroids) increased the initial Rubisco activation and RCA content under heat stress and heat plus drought stress conditions (Zhao et al. 2017). Moreover, studies on RCA have expanded beyond the target of just improving crop productivity. For instance, research was carried out on overexpressing a gene encoding a RCA-like protein in the microalgae Nannochloropsis oceanica in the prospects of improving biomass, which could lead to better carbon sequestration and higher biofuel production (Wei et al. 2017). Thus, it is evident that research pertaining to RCA not only benefits the global agricultural production, but also broadens to cover a wide range of areas that would help many other industries increasing productivity through an environmentally friendly approach.

In addition to the biochemical and genetic engineering works, the availability of whole genomes of many plant species, multiple databases, bioinformatics tools that allow the prediction of gene and protein structures and functions, and the Next Generation Sequencing through transcriptome data analysis, has aided in accelerating the process of identifying and predicting novel and putative heat responsive genes in plant germplasms (Kumar et al. 2017; Nagarajan and Gill 2018). This knowledge could also help us understand the structural and evolutionary changes occurred in different RCA isoforms that have similar or different functions, while enables certain RCAs like tobacco RCA that is a single isoform, to carry out activities of both long and short isoforms. The 
expression QTL (eQTL) mapping was carried out for maize RCA where the transcript and protein abundance under different growing seasons were evaluated and stably expressed eQTLs were identified that are related to maize RCA expression (Sun et al. 2017). The eQTL is a great tool in identifying factors that influence gene expression in vivo, where these determinants could be classified as cis- or trans-acting factors based on the proximity of eQTL to the gene of interest (Druka et al. 2010). Thus, the accessibility to information through these emerging methods enables us to better understand the structure and regulatory components of RCA in designing a more thermotolerant RCA with better Rubisco activation properties, as well as identifying important molecular markers for thermo-tolerant traits in plant breeding (Sun et al. 2017; Kumar et al. 2019), assisting to mitigate the thermo-lability of RCA and produce climatesmart crops. Different molecular targets could be used in increasing plant photosynthesis under heat stress, since parameters such as species, growth conditions, and climate participate in determining the limiting step of photosynthesis under stressful conditions (Yamori et al. 2014). Ogbaga et al. (2018) discussed the potential use of RCA from thermophilic cyanobacteria in the hope of expanding the thermo- tolerance window in agricultural crops without the expense of additional energy input for photorespiration, suggesting that this could be another area worth of further exploring.

In summary, RCA is one of the critical factors in photosynthesis and is a key that determines crop yield under heat stress conditions. As climate change evolves, RCA will emerge as a great tool for keeping food production in line with the world population growth in the future. While many methods are being tested in keeping RCA fully functional at elevated temperatures (Fig. 3), some appear to be very successful including the use of $L t R C A$ that encodes a naturally thermo-tolerant RCA (Wijewardene et al. 2020). Although these efforts in understanding how RCA maintains its activity at elevated temperatures and how RCA interacts with Rubisco at the molecular level must be continued, the thermal properties of RCA and its ability to respond to changing temperatures require substantial attention, and the genetic engineering of RCA in crops must ensure that enhancing RCA temperature resilience would not adversely affect its interaction with Rubisco, which will ultimately pave the way to improve plant biomass and yield under prevailing environmental conditions, thus safeguarding global food security in the future.

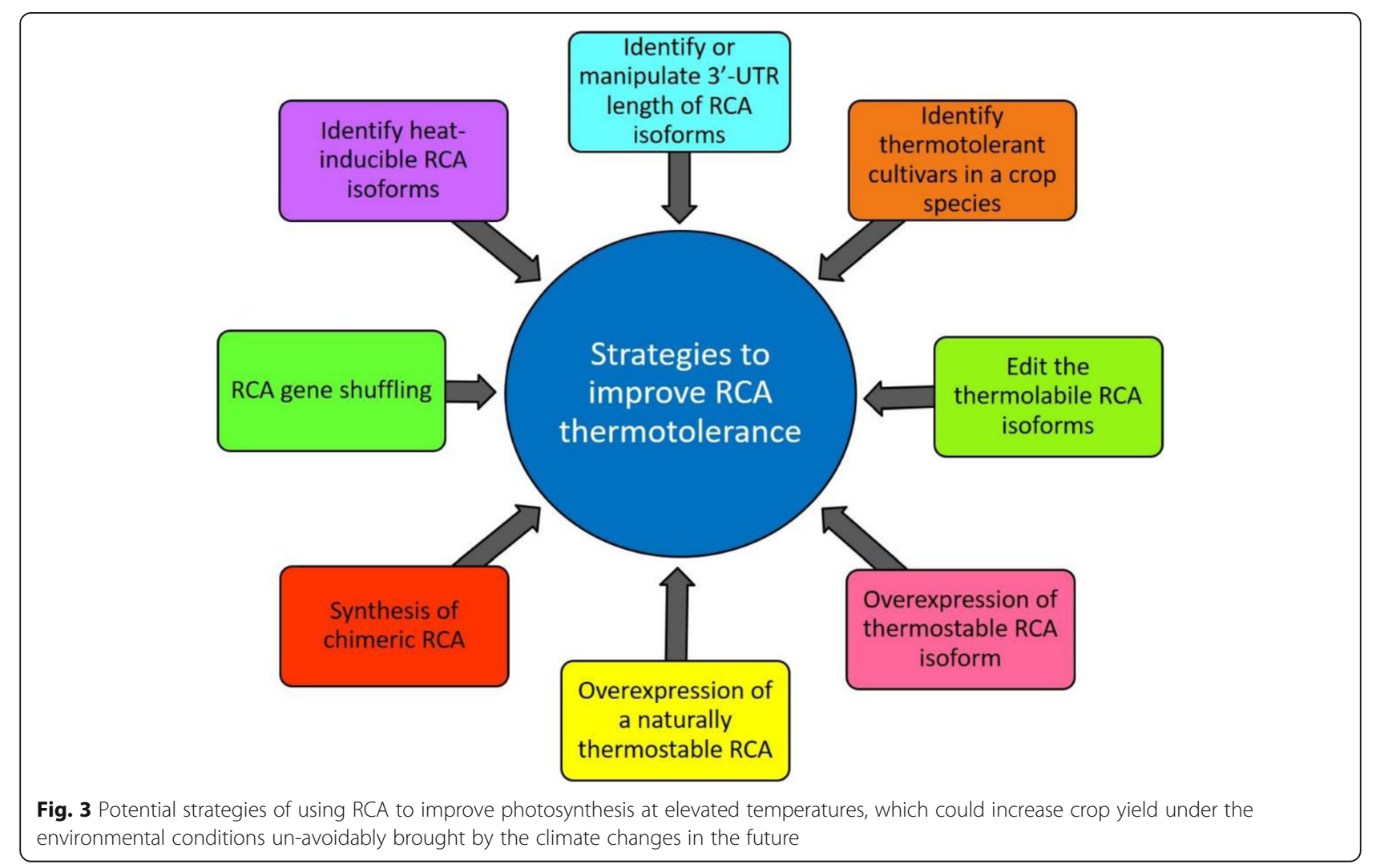




\section{Acknowledgements}

We thank all members of Dr. Hong Zhang's laboratory for reading and discussion of the manuscript before it was submitted for publication.

\section{Authors' contributions}

IW wrote the manuscript, GS and HZ revised the manuscript. The author(s) read and approved the final manuscript.

\section{Funding}

This work was supported by the Department of Biological Sciences and Graduate School of Texas Tech University. This work was also partially supported by grants to Guoxin Shen from the Key Research and Development Program of Zhejiang Province, China (2021C02002), and the Natural Science Foundation of China (32001104).

\section{Availability of data and materials}

Not applicable.

\section{Declarations}

Ethics approval and consent to participate

Not applicable.

\section{Consent for publication}

Not applicable.

\section{Competing interests}

The authors declare that they have no competing interests.

\section{Author details}

'Department of Biological Sciences, Texas Tech University, Lubbock, TX 79409, USA. '2 Zhejiang Academy of Agricultural Sciences, Hangzhou, Zhejiang Province, China.

Received: 16 April 2021 Accepted: 29 June 2021

Published online: 18 August 2021

\section{References}

Acuña-Galindo MA, Mason RE, Subramanian NK, Hays DB (2015) Meta-analysis of wheat QTL regions associated with adaptation to drought and heat stress. Crop Sci 55(2):477-492. https://doi.org/10.2135/cropsci2013.11.0793

Akter N, Islam MR (2017) Heat stress effects and management in wheat. A review. Agron Sustain Dev 37(5):37. https://doi.org/10.1007/s13593-017-0443-9

Ali M, Muhammad I, UI Haq S, Alam M, Khattak AM, Akhtar K, Ullah H, Khan A, Lu G, Gong ZH (2020) The CaChiVI2 gene of Capsicum annuum L. confers resistance against heat stress and infection of Phytophthora capsici. Front Plant Sci 11:219. https://doi.org/10.3389/fpls.2020.00219

Allakhverdiev SI, Kreslavski VD, Klimov W, Los DA, Carpentier R, Mohanty P (2008) Heat stress: an overview of molecular responses in photosynthesis. Photosynth Res 98(1-3):541-550. https://doi.org/10.1007/s11120-008-9331-0 Anjum NA (2015) Plant acclimation to environmental stress: a critical appraisal. Front Plant Sci 6:445. https://doi.org/10.3389/fpls.2015.00445

Antonovsky N, Gleizer S, Milo R (2017) Engineering carbon fixation in E. coli: from heterologous RuBisCO expression to the Calvin-Benson-Bassham cycle. Curr Opin Biotechnol 47:83-91. https://doi.org/10.1016/j.copbio.2017.06.006

Ayala-Ochoa A, Vargas-Suárez M, Loza-Tavera H, Leon P, Jimenez-Garcia L, Sanchez-De-Jimenez E (2004) In maize, two distinct ribulose 1, 5bisphosphate carboxylase/oxygenase activase transcripts have different day/ night patterns of expression. Biochimie. 86(7):439-449. https://doi.org/10.101 6/j.biochi.2004.06.007

Barta C, Dunkle AM, Wachter RM, Salvucci ME (2010) Structural changes associated with the acute thermal instability of Rubisco activase. Arch Biochem Biophys 499:17-25. https://doi.org/10.1016/..abb.2010.04.022

Bayramov S (2017) Changes in protein quantities of phosphoenolpyruvate carboxylase and Rubisco activase in various wheat genotypes. Saudi I Biol Sci 24(7):1529-1533. https://doi.org/10.1016/j.sjbs.2015.09.013

Bhat JY, Miličić G, Thieulin-Pardo G, Bracher A, Maxwell A, Ciniawsky S, MuellerCajar O, Engen JR, Hartl FU, Wendler P (2017a) Mechanism of enzyme repair by the AAA+ chaperone Rubisco activase. Mol Cell 67:744-756. e746. https:// doi.org/10.1016/j.molcel.2017.07.004
Bhat JY, Thieulin-Pardo G, Hartl FU, Hayer-Hartl M (2017b) Rubisco activases: AAA+ chaperones adapted to enzyme repair. Front Mol Biosci 4. https://doi. org/10.3389/fmolb.2017.00020

Bi H, Dong X, Liu P, Li Q, Ai X (2016) Influence of over expression of CsRCA on photosynthesis of cucumber seedlings under high temperature stress. J Appl Ecol 27:2308-2314. https://doi.org/10.13287/j.1001-9332.201607.028

Bi H, Liu P, Jiang Z, Ai X (2017) Overexpression of the rubisco activase gene improves growth and low temperature and weak light tolerance in Cucumis sativus. Physiol Plant 161:224-234. https://doi.org/10.1111/ppl.12587

Bi HH, Zhao Y, Li HH, Liu WX (2020) Wheat heat shock factor TaHsfA6f increases aba levels and enhances tolerance to multiple abiotic stresses in transgenic plants. Int J Mol Sci 21:9. https://doi.org/10.3390/ijms21093121

Busch FA, Sage RF (2017) The sensitivity of photosynthesis to $\mathrm{O}_{2}$ and $\mathrm{CO}_{2}$ concentration identifies strong Rubisco control above the thermal optimum. New Phytol 213:1036-1051. https://doi.org/10.1111/nph.14258

Carmo-Silva AE, Salvucci ME (2011) The activity of Rubisco's molecular chaperone, Rubisco activase, in leaf extracts. Photosynth Res 108(2-3):143-155. https:// doi.org/10.1007/s11120-011-9667-8

Carmo-Silva AE, Salvucci ME (2013) The regulatory properties of Rubisco activase differ among species and affect photosynthetic induction during light transitions. Plant Physiol 161:1645-1655. https://doi.org/10.1104/ pp.112.213348

Carmo-Silva E, Scales JC, Madgwick PJ, Parry MA (2015) Optimizing Rubisco and its regulation for greater resource use efficiency. Plant Cell Environ 38(9): 1817-1832. https://doi.org/10.1111/pce.12425

Chao M, Yin Z, Hao D, Zhang J, Song H, Ning A, Xu X, Yu D (2014) Variation in Rubisco activase (RCAB) gene promoters and expression in soybean [Glycine $\max ($ L.) Merr.]. J Exp Bot 65:47-59. https://doi.org/10.1093/jxb/ert346

Chen Y, Jin JH, Jiang QS, Yu CL, Chen J, Xu LG, Jiang DA (2014) Sodium bisulfite enhances photosynthesis in rice by inducing Rubisco activase gene expression. Photosynthetica. 52(3):475-478. https://doi.org/10.1007/s11099014-0044-7

Crafts-Brandner SJ, Salvucci ME (2000) Rubisco activase constrains the photosynthetic potential of leaves at high temperature and $\mathrm{CO}_{2}$. Proc Natl Acad Sci U S A 97(24):13430-13435. https://doi.org/10.1073/pnas.230451497

Crafts-Brandner SJ, Salvucci ME, Egli DB (1991) Fruit removal in soybean induces the formation of an insoluble form of ribulose-1, 5-bisphosphate carboxylase/oxygenase in leaf extracts. Planta. 183(2):300-306. https://doi. org/10.1007/BF00197802

Crafts-Brandner SJ, Van De Loo FJ, Salvucci ME (1997) The two forms of ribulose1, 5-bisphosphate carboxylase/oxygenase activase differ in sensitivity to elevated temperature. Plant Physiol 114:439-444. https://doi.org/10.1104/ pp.114.2.439

Cvikrová M, Gemperlová L, Dobrá J, Martincová O, Prásil IT, Gubis J, Vanková R (2012) Effect of heat stress on polyamine metabolism in proline-overproducing tobacco plants. Plant Sci 182:49-58. https://doi.org/10.1016/j.pla ntsci.2011.01.016

Degen GE, Worrall D, Carmo-Silva E (2020) An isoleucine residue acts as a thermal and regulatory switch in wheat Rubisco activase. Plant J 103(2):742751. https://doi.org/10.1111/tpj.14766

Demirevska-Kepova K, Holzer R, Simova-Stoilova L, Feller U (2005) Heat stress effects on ribulose-1, 5-bisphosphate carboxylase/oxygenase, Rubisco binding protein and Rubisco activase in wheat leaves. Biol Plant 49(4):521525. https://doi.org/10.1007/s10535-005-0045-2

Deridder BP, Salvucci ME (2007) Modulation of Rubisco activase gene expression during heat stress in cotton (Gossypium hirsutum L.) involves posttranscriptional mechanisms. Plant Sci 172(2):246-254. https://doi.org/10.1016/ j.plantsci.2006.08.014

Deridder BP, Shybut ME, Dyle MC, Kremling KA, Shapiro MB (2012) Changes at the $3^{\prime}$-untranslated region stabilize Rubisco activase transcript levels during heat stress in Arabidopsis. Planta. 236:463-476. https://doi.org/10.1007/s0042 5-012-1623-0

Druka A, Potokina E, Luo Z, Jiang N, Chen X, Kearsey M, Waugh R (2010) Expression quantitative trait loci analysis in plants. Plant Biotechnol J 8:10-27. https://doi.org/10.1111/j.1467-7652.2009.00460.x

Dubey PK, Singh GS, Abhilash PC (2020) Agriculture in a changing climate. Adaptive Agricultural Practices: Building resilience in a changing climate. Springer, Cham. pp 1-10. https://doi.org/10.1007/978-3-030-15519-3_1

Eckardt NA, Snyder GW, Portis AR Jr, Ogren WL (1997) Growth and photosynthesis under high and low irradiance of Arabidopsis thaliana antisense mutants with reduced ribulose-1, 5-bisphosphate carboxylase/ 
oxygenase activase content. Plant Physiol 113:575-586. https://doi.org/10.11 04/pp.113.2.575

El-Esawi MA, Al-Ghamdi AA, Ali HM, Ahmad M (2019) Overexpression of AtWRKY30 transcription factor enhances heat and drought stress tolerance in wheat (Triticum aestivum L.). Genes 10(2):163. https://doi.org/10.3390/genes1 0020163

Fahad S, Bajwa AA, Nazir U, Anjum SA, Farooq A, Zohaib A, Sadia S, Nasim W, Adkins S, Saud S (2017) Crop production under drought and heat stress: plant responses and management options. Front Plant Sci 8:1147. https://doi. org/10.3389/fpls.2017.01147

Fan Y, Ma C, Huang Z, Abid M, Jiang S, Dai T, Zhang W, Ma S, Jiang D, Han X (2018) Heat priming during early reproductive stages enhances thermotolerance to post-anthesis heat stress via improving photosynthesis and plant productivity in winter wheat (Triticum aestivum L.). Front Plant Sci 9 : 805. https://doi.org/10.3389/fpls.2018.00805

Flecken M, Wang H, Popilka L, Hartl FU, Bracher A, Hayer-Hartl M (2020) Dual role of a rubisco activase in metabolic repair and carboxysome organization. BioRxiv, Cell 91. https://doi.org/10.1101/2020.05.16.099382

Fukayama H, Abe R, Uchida N (2010) SDS-dependent proteases induced by ABA and its relation to Rubisco and Rubisco activase contents in rice leaves. Plant Physiol Biochem 48:808-812. https://doi.org/10.1016/j.plaphy.2010.08.002

Fukayama H, Mizumoto A, Ueguchi C, Katsunuma J, Morita R, Sasayama D, Hatanaka T, Azuma T (2018) Expression level of rubisco activase negatively correlates with rubisco content in transgenic rice. Photosynth Res 137(3): 465-474. https://doi.org/10.1007/s11120-018-0525-9

Fukayama H, Uchida N, Azuma T, Yasuda T (1996) Relationships between photosynthetic activity and the amounts of Rubisco activase and Rubisco in rice leaves from emergence through senescence. Japanese J Crop Sci 65(2): 296-302. https://doi.org/10.1626/jcs.65.296

Fukayama H, Ueguchi C, Nishikawa K, Katoh N, Ishikawa C, Masumoto C, Hatanaka T, Misoo S (2012) Overexpression of Rubisco activase decreases the photosynthetic $\mathrm{CO}_{2}$ assimilation rate by reducing rubisco content in rice leaves. Plant Cell Physiol 53:976-986. https://doi.org/10.1093/pcp/pcs042

Gaxiola RA, Li JS, Undurraga S, Dang LM, Allen GJ, Alper SL, Fink GR (2001) Drought- and salt-tolerant plants result from overexpression of the AVP1 $\mathrm{H}^{+}$pump. Proc Natl Acad Sci U S A 98(20):11444-11449. https://doi.org/10.1073/ pnas.191389398

Ghosh S, Kamble NU, Verma P, Salvi P, Petla BP, Roy S, Rao V, Hazra A, Varshney V, Kaur H, Majee M (2020) Arabidopsis protein I-ISOASPARTYL METHYLTRANSFERASE repairs isoaspartyl damage to antioxidant enzymes and increases heat and oxidative stress tolerance. J Biol Chem 295(3):783799. https://doi.org/10.1074/jbc.RA119.010779

Hammond ET, Andrews TJ, Mott KA, Woodrow IE (1998) Regulation of Rubisco activation in antisense plants of tobacco containing reduced levels of Rubisco activase. Plant J 14:101-110. https://doi.org/10.1046/j.1365-313X.1 998.00103.x

Hartl M, FüßI M, Boersema PJ, Jost JO, Kramer K, Bakirbas A, Sindlinger J, Plöchinger M, Leister D, Uhrig G (2017) Lysine acetylome profiling uncovers novel histone deacetylase substrate proteins in Arabidopsis. Mol Syst Biol 13: 949. https://doi.org/10.15252/msb.20177819

Hasse D, Larsson AM, Andersson I (2015) Structure of Arabidopsis thaliana Rubisco activase. Acta Crystallogr D Biol 71:800-808. https://doi.org/10.1107/ S1399004715001182

He Z, Von Caemmerer S, Hudson GS, Price GD, Badger MR, Andrews TJ (1997) Ribulose-1, 5-bisphosphate carboxylase/oxygenase activase deficiency delays senescence of ribulose-1, 5-bisphosphate carboxylase/oxygenase but progressively impairs its catalysis during tobacco leaf development. Plant Physiol 115(4):1569-1580. https://doi.org/10.1104/pp.115.4.1569

Henderson JN, Kuriata AM, Fromme R, Salvucci ME, Wachter RM (2011) Atomic resolution $\mathrm{x}$-ray structure of the substrate recognition domain of higher plant ribulose-bisphosphate carboxylase/oxygenase (Rubisco) activase. J Biol Chem 286(41):35683-35688. https://doi.org/10.1074/jbc.C111.289595

Hong J, Jiang DA, Weng XY, Wang WB, Hu DW (2005) Leaf anatomy, chloroplast ultrastructure, and cellular localisation of ribulose-1,5-bisphosphate carboxylase/oxygenase (RUBPCO) and RuBPCO activase in Amaranthus tricolor L. Photosynthetica. 43(4):519-528. https://doi.org/10.1007/s11099-005-0084-0

Ipcc IPOCC, Bongaarts J (2019) Special report on global warming of $1.5^{\circ} \mathrm{C}$ (SR15). Popul Dev Rev 45(1):251-252. https://doi.org/10.1111/padr.12234

Jiang Y, Wang J, Tao X, Zhang Y (2013) Characterization and expression of Rubisco activase genes in Ipomoea batatas. Mol Biol Rep 40(11):6309-6321. https://doi.org/10.1007/s11033-013-2744-7
Jiang Y, Yong B, Chen J, Zhang Y (2014) Two Rubisco activase genes from ipomoea Batatas have different roles in photosynthesis of Arabidopsis. Pak J Bot 46:1381À1388

Jin SH, Hong J, Li XQ, Jiang DA (2006) Antisense inhibition of Rubisco activase increases Rubisco content and alters the proportion of Rubisco activase in stroma and thylakoids in chloroplasts of rice leaves. Ann Bot 97(5):739-744. https://doi.org/10.1093/aob/mcl025

Jurczyk B, Hura K, Trzemecka A, Rapacz M (2015a) Evidence for alternative splicing mechanisms in meadow fescue (Festuca pratensis) and perennial ryegrass (Lolium perenne) Rubisco activase gene. J Plant Physiol 176:61-64. https://doi.org/10.1016/j.jplph.2014.11.011

Jurczyk B, Pociecha E, Grzesiak M, Rapacz M (2015b) Enhanced expression of Rubisco activase confers to increase in Rubisco activity during cold acclimation in Lolium perenne. Procedia Environ Sci 29:213-214. https://doi. org/10.1016/j.proenv.2015.07.268

Khush GS (2005) What it will take to feed 5.0 billion rice consumers in 2030. Plant Mol Biol 59(1):1-6. https://doi.org/10.1007/s11103-005-2159-5

Kim K, Portis AR Jr (2005) Temperature dependence of photosynthesis in Arabidopsis plants with modifications in Rubisco activase and membrane fluidity. Plant Cell Physiol 46:522-530. https://doi.org/10.1093/ pcp/pci052

Kim SY, Harvey CM, Giese J, Lassowskat I, Singh V, Cavanagh AP, Spalding MH, Finkemeier I, Ort DR, Huber SC (2019) In vivo evidence for a regulatory role of phosphorylation of Arabidopsis Rubisco activase at the Thr78 site. Proc Natl Acad Sci U S A 116(37):18723-18731. https://doi.org/10.1073/pnas.1812 916116

Kumar A, Li CS, Portis AR (2009) Arabidopsis thaliana expressing a thermostable chimeric Rubisco activase exhibits enhanced growth and higher rates of photosynthesis at moderately high temperatures. Photosynth Res 100(3):143153. https://doi.org/10.1007/s11120-009-9438-y

Kumar RR, Goswami S, Dubey K, Singh K, Singh JP, Kumar A, Rai GK, Singh SD, Bakshi S, Singh B (2019) RuBisCo activase - a catalytic chaperone involved in modulating the RuBisCo activity and heat stress-tolerance in wheat. J Plant Biochem Biotechnol 28(1):63-75. https://doi.org/10.1007/ s13562-018-0463-9

Kumar RR, Goswami S, Shamim M, Dubey K, Singh K, Singh S, Kala YK, Niraj RR, Sakhrey A, Singh GP (2017) Exploring the heat-responsive chaperones and microsatellite markers associated with terminal heat stress tolerance in developing wheat. Funct Integr Genomics 17:621-640. https://doi.org/10.1 007/s10142-017-0560-1

Kumar RR, Goswami S, Singh K, Dubey K, Singh S, Sharma R, Verma N, Kala YK, Rai GK, Grover M (2016) Identification of putative RuBisCo Activase (TaRca1)the catalytic chaperone regulating carbon assimilatory pathway in wheat (Triticum aestivum) under the heat stress. Front Plant Sci 7:986. https://doi. org/10.3389/fpls.2016.00986

Kurek I, Chang TK, Bertain SM, Madrigal A, Liu L, Lassner MW, Zhu GH (2007) Enhanced thermostability of Arabidopsis Rubisco activase improves photosynthesis and growth rates under moderate heat stress. Plant Cell 19(10):3230-3241. https://doi.org/10.1105/tpc.107.054171

Kuriata AM, Chakraborty M, Henderson JN, Hazra S, Serban AJ, Pham TV, Levitus M, Wachter RM (2014) ATP and magnesium promote cotton short-form ribulose-1, 5-bisphosphate carboxylase/oxygenase (Rubisco) activase hexamer formation at low micromolar concentrations. Biochemistry. 53: 7232-7246. https://doi.org/10.1021/bi500968h

Lamaoui M, Jemo M, Datla R, Bekkaoui F (2018) Heat and drought stresses in crops and approaches for their mitigation. Front Chem 6:26. https://doi.org/1 $0.3389 /$ fchem.2018.00026

Law DR, Crafts-Brandner SJ, Salvucci ME (2001) Heat stress induces the synthesis of a new form of ribulose-1, 5-bisphosphate carboxylase/oxygenase activase in cotton leaves. Planta. 214:117-125

Law RD, Crafts-Brandner SJ (1999) Inhibition and acclimation of photosynthesis to heat stress is closely correlated with activation of ribulose-1, 5bisphosphate carboxylase/oxygenase. Plant Physiol 120(1):173-182. https:// doi.org/10.1104/pp.120.1.173

Law RD, Crafts-Brandner SJ (2001) High temperature stress increases the expression of wheat leaf ribulose-1, 5-bisphosphate carboxylase/oxygenase activase protein. Arch Biochem Biophys 386(2):261-267. https://doi.org/10.1 006/abbi.2000.2225

Li C, Salvucci ME, Portis AR (2005) Two residues of Rubisco activase involved in recognition of the Rubisco substrate. J Biol Chem 280(26):24864-24869. https://doi.org/10.1074/jbc.M503547200 
Lin YH, Huang LF, Hase T, Huang HE, Feng TY (2015) Expression of plant ferredoxin-like protein (PFLP) enhances tolerance to heat stress in Arabidopsis thaliana. N Biotechnol 32(2):235-242. https://doi.org/10.1016/j.nbt.2014.12.001

Liu X, Huang B (2008) Photosynthetic acclimation to high temperatures associated with heat tolerance in creeping bentgrass. J Plant Physiol 165: 1947-1953. https://doi.org/10.1016/j.jplph.2008.05.001

Liu Y, Tang L, Qiu X, Liu B, Chang X, Liu L, Zhang X, Cao W, Zhu Y (2020) Impacts of 1.5 and $2.0^{\circ} \mathrm{C}$ global warming on rice production across China. Agric For Meteorol 284:107900. https://doi.org/10.1016/j.a grformet.2020.107900

Liu Z, Taub CC, Mcclung CR (1996) Identification of an Arabidopsis thaliana ribulose-1, 5-bisphosphate carboxylase/oxygenase activase (RCA) minimal promoter regulated by light and the circadian clock. Plant Physiol 112:43-51. https://doi.org/10.1104/pp.112.1.43

Loganathan N, Tsai YCC, Mueller-Cajar O (2016) Characterization of the heterooligomeric red-type rubisco activase from red algae. Proc Natl Acad Sci U S A 113:14019-14024. https://doi.org/10.1073/pnas.1610758113

Martínez-Barajas E, Molina-Galán J, De Jimenez ES (1997) Regulation of Rubisco activity during grain-fill in maize: possible role of Rubisco activase. J Agric Sci 128(2):155-161. https://doi.org/10.1017/S002185969600408X

Mate CJ, Hudson GS, Von Caemmerer S, Evans JR, Andrews TJ (1993) Reduction of ribulose bisphosphate carboxylase activase levels in tobacco (Nicotiana tabacum) by antisense RNA reduces ribulose bisphosphate carboxylase carbamylation and impairs photosynthesis. Plant Physiol 102:1119-1128. https://doi.org/10.1104/pp.102.4.1119

Minhas PS, Rane J, Pasala RK (2017) Abiotic stresses in agriculture: an overview. In: Abiotic stress Management for Resilient Agriculture. Springer, Singapore, pp 3-8. https://doi.org/10.1007/978-981-10-5744-1_1

Mueller-Cajar O, Whitney SM (2008) Directing the evolution of Rubisco and Rubisco activase: first impressions of a new tool for photosynthesis research. Photosynth Res 98(1-3):667-675. https://doi.org/10.1007/s11120008-9324-z

Nadeem M, Li J, Wang M, Shah L, Lu S, Wang X, Ma C (2018) Unraveling field crops sensitivity to heat stress: mechanisms, approaches, and future prospects. Agronomy. 8:128. https://doi.org/10.3390/agronomy8070128

Nagarajan R, Gill KS (2018) Evolution of Rubisco activase gene in plants. Plant Mol Biol 96(1-2):69-87. https://doi.org/10.1007/s11103-017-0680-y

Nalluri N, Karri VR (2020) Recent advances in genetic manipulation of crops: a promising approach to address the global food and industrial applications. Plant Sci Today 7:70-92

Ogbaga CC, Stepien P, Athar HUR, Ashraf M (2018) Engineering Rubisco activase from thermophilic cyanobacteria into high-temperature sensitive plants. Crit Rev Biotechnol 38(4):559-572. https://doi.org/10.1080/07388551.2017.1378998

Ott CM, Smith BD, Portis AR, Spreitzer RJ (2000) Activase region on chloroplast Ribulose-1, 5-bisphosphate carboxylase/oxygenase nonconservative substitution in the large subunit alters species specificity of protein interaction. J Biol Chem 275(34):26241-26244. https://doi.org/10.1074/jbc. M004580200

Panzade KP, Vishwakarma H, Padaria JC (2020) Heat stress inducible cytoplasmic isoform of ClpB1 from Z. nummularia exhibits enhanced thermotolerance in transgenic tobacco. Mol Biol Rep 47(5):3821-3831. https://doi.org/10.1007/ s11033-020-05472-w

Parry MAJ, Andralojc PJ, Mitchell RA, Madgwick PJ, Keys AJ (2003) Manipulation of Rubisco: the amount, activity, function and regulation. J Exp Bot 54(386): 1321-1333. https://doi.org/10.1093/jxb/erg141

Parry MAJ, Andralojc PJ, Scales JC, Salvucci ME, Carmo-Silva AE, Alonso H, Whitney SM (2013) Rubisco activity and regulation as targets for crop improvement. J Exp Bot 64:717-730. https://doi.org/10.1093/jxb/ers336

Parry M AJ, Madgwick PJ, Carvalho JFC, Andralojc PJ (2007) Prospects for increasing photosynthesis by overcoming the limitations of Rubisco. J Agric Sci 145(1):31-43. https://doi.org/10.1017/S0021859606006666

Pasapula V, Shen G, Kuppu S, Paez-Valencia J, Mendoza M, Hou P, Chen J, Qiu X, Zhu L, Zhang X, Auld D, Blumwald E, Zhang H, Gaxiola R, Payton P (2011) Expression of an Arabidopsis vacuolar $\mathrm{H}^{+}$-pyrophosphatase gene (AVP1) in cotton improves drought- and salt tolerance and increases fibre yield in the field conditions. Plant Biotechnol J 9(1):88-99. https://doi.org/10.1111/j.14677652.2010.00535.x

Perdomo JA, Capó-Bauçà S, Carmo-Silva E, Galmés J (2017) Rubisco and rubisco activase play an important role in the biochemical limitations of photosynthesis in rice, wheat, and maize under high temperature and water deficit. Front Plant Sci 8:490. https://doi.org/10.3389/fpls.2017.00490
Perdomo JA, Degen GE, Worrall D, Carmo-Silva E (2019) Rubisco activation by wheat Rubisco activase isoform $2 \beta$ is insensitive to inhibition by ADP. Biochem J 476:2595-2606. https://doi.org/10.1042/BCJ20190110

Portis AR (2003) Rubisco activase - Rubisco's catalytic chaperone. Photosynth Res 75:11-27. https://doi.org/10.1023/A:1022458108678

Portis AR Jr (1990) Rubisco activase. Biochim Biophys Acta 1015:15-28. https:// doi.org/10.1016/0005-2728(90)90211-L

Portis AR Jr, Li C, Wang D, Salvucci ME (2008) Regulation of Rubisco activase and its interaction with Rubisco. J Exp Bot 59(7):1597-1604. https://doi.org/10.1 093/jxb/erm240

Portis AR Jr, Salvucci ME (2002) The discovery of Rubisco activase-yet another story of serendipity. Photosynth Res 73(1/3):257-264. https://doi.org/10.1 023/A:1020423802875

Qi Y, Liu Y, Zhang Z, Gao J, Guan Z, Fang W, Chen S, Chen F, Jiang J (2018) The over-expression of a chrysanthemum gene encoding an RNA polymerase II CTD phosphatase-like 1 enzyme enhances tolerance to heat stress. Hortic Res 5(1):1-10. https://doi.org/10.1038/s41438-018-0037-y

Qian J, Rodermel SR (1993) Ribulose-1, 5-bisphosphate carboxylase/oxygenase activase cDNAs from Nicotiana tabacum. Plant Physiol 102(2):683-684. https://doi.org/10.1104/pp.102.2.683

Qu D, Song Y, Li W, Pei X, Wang Z, Jia S, Zhang Y (2011) Isolation and characterization of the organ-specific and light-inducible promoter of the gene encoding rubisco activase in potato (Solanum tuberosum). Genet Mol Res 10(2):621-631. https://doi.org/10.4238/vol10-2gmr1088

Qu Y, Sakoda K, Fukayama H, Kondo E, Suzuki Y, Makino A, Yamori W (2021) Overexpression of both Rubisco and Rubisco activase rescues rice photosynthesis and biomass under heat stress. Plant Cell Environ. https://doi. org/10.1111/pce.14051

Ristic Z, Momčilović I, Bukovnik U, Prasad PW, Fu J, Deridder BP, Elthon TE, Mladenov N (2009) Rubisco activase and wheat productivity under heatstress conditions. J Exp Bot 60:4003-4014. https://doi.org/10.1093/jxb/erp241

Rokka A, Zhang L, Aro EM (2001) Rubisco activase: an enzyme with a temperature-dependent dual function? Plant J 25:463-471. https://doi.org/1 0.1046/j.1365-313x.2001.00981.x

Rollins J, Habte E, Templer S, Colby T, Schmidt J, Von Korff M (2013) Leaf proteome alterations in the context of physiological and morphological responses to drought and heat stress in barley (Hordeum vulgare L.). J Exp Bot 64(11):3201-3212. https://doi.org/10.1093/jxb/ert158

Rundle SJ, Zielinski RE (1991) Organization and expression of two tandemly oriented genes encoding ribulosebisphosphate carboxylase/oxygenase activase in barley. J Biol Chem 266:4677-4685. https://doi.org/10.1016/S00219258(19)67702-1

Ruuska SA, Andrews TJ, Badger MR, Price GD, Von Caemmerer S (2000) The role of chloroplast electron transport and metabolites in modulating Rubisco activity in tobacco. Insights from transgenic plants with reduced amounts of cytochrome b/fcomplex or glyceraldehyde 3-phosphate dehydrogenase. Plant Physiol 122:491-504. https://doi.org/10.1104/pp.122.2.491

Sage RF, Way DA, Kubien DS (2008) Rubisco, rubisco activase, and global climate change. J Exp Bot 59:1581-1595. https://doi.org/10.1093/jxb/ern053

Salesse-Smith CE, Sharwood RE, Busch FA, Kromdijk J, Bardal V, Stern DB (2018) Overexpression of Rubisco subunits with RAF1 increases Rubisco content in maize. Nat Plants 4(10):802-810. https://doi.org/10.1038/s41477-018-0252-4

Salvucci ME (2008) Association of Rubisco activase with chaperonin-60ß: a possible mechanism for protecting photosynthesis during heat stress. J Exp Bot 59(7):1923-1933. https://doi.org/10.1093/jxb/erm343

Salvucci ME, Crafts-Brandner SJ (2004) Mechanism for deactivation of Rubisco under moderate heat stress. Physiol Plant 122(4):513-519. https://doi.org/1 0.1111/j.1399-3054.2004.00419.x

Salvucci ME, Crafts-Brandner SJ (2004a) Inhibition of photosynthesis by heat stress: the activation state of Rubisco as a limiting factor in photosynthesis. Physiol Plant 120:179-186. https://doi.org/10.1093/jxb/erm343

Salvucci ME, Crafts-Brandner SJ (2004b) Relationship between the heat tolerance of photosynthesis and the thermal stability of rubisco activase in plants from contrasting thermal environments. Plant Physiol 134:1460-1470. https://doi. org/10.1104/pp.103.038323

Salvucci ME, Deridder BP, Portis AR Jr (2006) Effect of activase level and isoform on the thermotolerance of photosynthesis in Arabidopsis. J Exp Bot 57:37933799. https://doi.org/10.1093/jxb/erl140

Salvucci ME, Ogren WL (1996) The mechanism of Rubisco activase: insights from studies of the properties and structure of the enzyme. Photosynth Res 47(1): 1-11. https://doi.org/10.1007/BF00017748 
Salvucci ME, Osteryoung KW, Crafts-Brandner SJ, Vierling E (2001) Exceptional sensitivity of Rubisco activase to thermal denaturation in vitro and in vivo. Plant Physiol 127:1053-1064. https://doi.org/10.1104/pp.010357

Salvucci ME, Portis AR, Ogren WL (1985) A soluble chloroplast protein catalyzes ribulosebisphosphate carboxylase/oxygenase activation in vivo. Photosynth Res 7:193-201. https://doi.org/10.1007/BF00037012

Salvucci ME, Van De Loo FJ, Stecher D (2003) Two isoforms of Rubisco activase in cotton, the products of separate genes not alternative splicing. Planta 216: 736-744. https://doi.org/10.1007/s00425-002-0923-1

Salvucci ME, Werneke JM, Ogren WL, Portis AR (1987) Purification and species distribution of Rubisco activase. Plant Physiol 84(3):930-936. https://doi.org/1 0.1104/pp.84.3.930

Sanchez De Jimenez E, Medrano L, Martinez-Barajas E (1995) Rubisco activase, a possible new member of the molecular chaperone family. Biochemistry 34(9):2826-2831. https://doi.org/10.1021/bi00009a012

Sándor R, Picon-Cochard C, Martin R, Louault F, Klumpp K, Borras D, Bellocchi G (2018) Plant acclimation to temperature: developments in the pasture simulation model. Field Crop Res 222:238-255. https://doi.org/10.1016/j.fcr.2 017.05.030

Scafaro AP, Atwell BJ, Muylaert S, Reusel BV, Ruiz GA, Rie JV, Gallé A (2018) A thermotolerant variant of Rubisco activase from a wild relative improves growth and seed yield in rice under heat stress. Front Plant Sci 9:1663. https://doi.org/10.3389/fpls.2018.01663

Scafaro AP, Bautsoens N, Den Boer B, Van Rie J, Galle A (2019) A conserved sequence from heat-adapted species improves Rubisco activase thermostability in wheat. Plant Physiol 181(1):43-54. https://doi.org/10.1104/ pp.19.00425

Scafaro AP, Galle A, Van Rie J, Carmo-Silva E, Salvucci ME, Atwell BJ (2016) Heat tolerance in a wild Oryza species is attributed to maintenance of Rubisco activation by a thermally stable Rubisco activase ortholog. New Phytol 211(3):899-911. https://doi.org/10.1111/nph.13963

Shan X, Wang J, Chua L, Jiang D, Peng W, Xie D (2011) The role of Arabidopsis Rubisco activase in jasmonate-induced leaf senescence. Plant Physiol 155(2): 751-764. https://doi.org/10.1104/pp.110.166595

Sharkey TD (2005) Effects of moderate heat stress on photosynthesis: importance of thylakoid reactions, rubisco deactivation, reactive oxygen species, and thermotolerance provided by isoprene. Plant Cell Environ 28:269-277. https://doi.org/10.1111/j.1365-3040.2005.01324x

Sharkey TD, Badger MR, Von Caemmerer S, Andrews TJ (2001) Increased heat sensitivity of photosynthesis in tobacco plants with reduced Rubisco activase. Photosynth Res 67:147-156. https://doi.org/10.1023/A:1010633823747

Shen J, Orozco E, Ogren W (1991) Expression of the two isoforms of spinach ribulose 1, 5-bisphosphate carboxylase activase and essentiality of the conserved lysine in the consensus nucleotide-binding domain. J Biol Chem 266:8963-8968. https://doi.org/10.1016/S0021-9258(18)31538-2

Shivhare D, Mueller-Cajar O (2017a) In vitro characterization of thermostable CAM Rubisco activase reveals a Rubisco interacting surface loop. Plant Physiol 174(3):1505-1516. https://doi.org/10.1104/pp.17.00554

Shivhare D, Mueller-Cajar O (2017b) Rubisco Activase: the molecular chiropractor of the world's most abundant protein. Photosynth Bioener 159. https://doi. org/10.1142/9789813230309_0008

Shivhare D, Ng J, Tsai YCC, Mueller-Cajar O (2019) Probing the rice Rubisco-Rubisco activase interaction via subunit heterooligomerization. Proc Natl Acad Sci U S A 116(48):24041-24048. https://doi.org/10.1073/pnas.1914245116

Singh B, Salaria N, Thakur K, Kukreja S, Gautam S, Goutam U (2019) Functional genomic approaches to improve crop plant heat stress tolerance. F1000Res 8:1721. https://doi.org/10.12688/f1000research.19840.1

Somerville CR, Portis AR, Ogren WL (1982) A mutant of Arabidopsis thaliana which lacks activation of RuBP carboxylase in vivo. Plant Physiol 70:381-387. https://doi.org/10.1104/pp.70.2.381

Stotz M, Mueller-Cajar O, Ciniawsky S, Wendler P, Hartl FU, Bracher A, Hayer-Hartl M (2011) Structure of green-type Rubisco activase from tobacco. Nat Struct Mol Biol 18(12):1366-1370. https://doi.org/10.1038/nsmb.2171

Suganami M, Suzuki Y, Kondo E, Nishida S, Konno S, Makino A (2020) Effects of overproduction of Rubisco Activase on Rubisco content in transgenic rice grown at different N levels. Int J Mol Sci 21:1626. https://doi.org/10.3390/ ijms21051626

Suganami M, Suzuki Y, Sato T, Makino A (2018) Relationship between Rubisco activase and Rubisco contents in transgenic rice plants with overproduced or decreased Rubisco content. Soil Sci Plant Nutr 64:352-359. https://doi.org/1 $0.1080 / 00380768.2018 .1433455$
Suganami M, Suzuki Y, Tazoe Y, Yamori W, Makino A (2021) Co-overproducing Rubisco and Rubisco activase enhances photosynthesis in the optimal temperature range in rice. Plant Physiol 185(1):108-119. https://doi.org/10.1 093/plphys/kiaa026

Sun Q, Zhang Y, Chen B, Jia B, Zhang Z, Cui M, Kan X, Shi H, Deng D, Yin Z (2017) Expression quantitative trait loci analysis of the rubisco activase gene in maize. Photosynthetica. 55(2):329-337. https://doi.org/10.1007/s11099-016-0242-6

Suzuki Y, Miyamoto T, Yoshizawa R, Mae T, Makino A (2009) Rubisco content and photosynthesis of leaves at different positions in transgenic rice with an overexpression of RBCS. Plant Cell Environ 32(4):417-427. https://doi.org/1 0.1111/j.1365-3040.2009.01937.x

To KY, Suen DF, Chen SCG (1999) Molecular characterization of ribulose-1, 5bisphosphate carboxylase/oxygenase activase in rice leaves. Planta. 209:6676. https://doi.org/10.1007/s004250050607

Tsai YCC, Lapina MC, Bhushan S, Mueller-Cajar O (2015) Identification and characterization of multiple rubisco activases in chemoautotrophic bacteria. Nat Commun 6(1):8883. https://doi.org/10.1038/ncomms9883

Ulukan H (2009) The evolution of cultivated plant species: classical plant breeding versus genetic engineering. Plant Syst Evol 280(3-4):133-142. https://doi.org/10.1007/s00606-008-0118-8

Vargas-Suárez M, Ayala-Ochoa A, Lozano-Franco J, García-Torres I, Díaz-Quiñonez A, Ortíz-Navarrete VF, Sánchez-De-Jiménez E (2004) Rubisco activase chaperone activity is regulated by a post-translational mechanism in maize leaves. J Exp Bot 55(408):2533-2539. https://doi.org/10.1093/jxb/erh268

Wahid A, Gelani S, Ashraf M, Foolad MR (2007) Heat tolerance in plants: an overview. Environ Exp Bot 61:199-223. https://doi.org/10.1016/j.envexpbot.2007.05.011

Walter A, Finger R, Huber R, Buchmann N (2017) Opinion: smart farming is key to developing sustainable agriculture. Proc Natl Acad Sci U S A 114:6148-6150. https://doi.org/10.1073/pnas.1707462114

Wang D, Li XF, Zhou ZJ, Feng XP, Yang WJ, Jiang DA (2010) Two Rubisco activase isoforms may play different roles in photosynthetic heat acclimation in the rice plant. Physiol Plant 139:55-67. https://doi.org/10.1111/j.1399-3054.2009.01344.x

Wang D, Lu Q, Li X, Jiang Q, Wu J, Jiang D (2009) Relationship between Rubisco activase isoform levels and photosynthetic rate in different leaf positions of rice plant. Photosynthetica. 47(4):621-629. https://doi.org/10.1007/s11099-009-0089-1

Wang J, Gao X, Dong J, Tian X, Wang J, Palta JA, Xu S, Fang Y, Wang Z (2020) Over-expression of the heat-responsive wheat gene TaHSP23.9 in transgenic Arabidopsis conferred tolerance to heat and salt stress. Front Plant Sci 11. https://doi.org/10.3389/fpls.2020.00243

Wang X, Huang W, Liu J, Yang Z, Huang B (2017) Molecular regulation and physiological functions of a novel FaHsfA2c cloned from tall fescue conferring plant tolerance to heat stress. Plant Biotechnol J 15:237-248. https://doi.org/10.1111/pbi.12609

Wang ZY, Snyder GW, Esau BD, Portis AR, Ogren WL (1992) Species-dependent variation in the interaction of substrate-bound ribulose-1, 5-bisphosphate carboxylase/oxygenase (Rubisco) and Rubisco activase. Plant Physiol 100: 1858-1862. https://doi.org/10.1104/pp.100.4.1858

Watillon B, Kettmann R, Boxus P, Burny A (1993) Developmental and circadian pattern of rubisco activase mRNA accumulation in apple plants. Plant Mol Biol 23:501-509. https://doi.org/10.1007/BF00019298

Wei L, Wang Q, Xin Y, Lu Y, Xu J (2017) Enhancing photosynthetic biomass productivity of industrial oleaginous microalgae by overexpression of RuBisCO activase. Algal Res 27:366-375. https://doi.org/10.1016/j.algal.2017.07.023

Wen J, Jiang F, Weng Y, Sun M, Shi X, Zhou Y, Yu L, Wu Z (2019) Identification of heat-tolerance QTLs and high-temperature stress-responsive genes through conventional QTL mapping, QTL-seq and RNA-seq in tomato. BMC Plant Biol 19:398. https://doi.org/10.1186/s12870-019-2008-3

Werneke JM, Chatfield JM, Ogren WL (1989) Alternative mRNA splicing generates the two ribulosebisphosphate carboxylase/oxygenase activase polypeptides in spinach and Arabidopsis. Plant Cell 1:815-825. https://doi.org/10.1105/tpc.1.8.815

Weston DJ, Bauerle WL, Swire-Clark GA, Moore BD, Baird WW (2007) Characterization of Rubisco activase from thermally contrasting genotypes of Acer rubrum (Aceraceae). Am J Bot 94:926-934. https://doi.org/10.3732/ajb.94.6.926

Wijewardene I, Mishra N, Sun L, Smith J, Zhu X, Payton P, Shen G, Zhang H (2020) Improving drought-, salinity-, and heat-tolerance in transgenic plants by co-overexpressing Arabidopsis vacuolar pyrophosphatase gene AVP1 and Larrea Rubisco activase gene RCA. Plant Sci 296:110499. https://doi.org/10.101 6/j.plantsci.2020.110499

Wilson RH, Thieulin-Pardo G, Hartl FU, Hayer-Hartl M (2019) Improved recombinant expression and purification of functional plant Rubisco. FEBS Lett 593:611-621. https://doi.org/10.1002/1873-3468.13352 
Wostrikoff K, Clark A, Sato S, Clemente T, Stern D (2012) Ectopic expression of Rubisco subunits in maize mesophyll cells does not overcome barriers to cell type-specific accumulation. Plant Physiol 160(1):419-432. https:/doi.org/10.1104/pp.112.195677

Xu K, He B, Zhou S, Li Y, Zhang Y (2010) Cloning and characterization of the Rubisco activase gene from Ipomoea batatas (L.) Lam. Mol Biol Rep 37:661. https://doi.org/10.1007/s11033-009-9510-x

Xue GP, Drenth J, Mcintyre CL (2015) TaHsfA6f is a transcriptional activator that regulates a suite of heat stress protection genes in wheat (Triticum aestivum L.) including previously unknown Hsf targets. J Exp Bot 66:1025-1039. https://doi.org/10.1093/jxb/eru462

Yamori W, Hikosaka K, Way DA (2014) Temperature response of photosynthesis in C3, C4, and CAM plants: temperature acclimation and temperature adaptation. Photosynth Res 119:101-117. https://doi.org/10.1007/s11120-013-9874-6

Yamori W, Masumoto C, Fukayama H, Makino A (2012) Rubisco activase is a key regulator of non-steady-state photosynthesis at any leaf temperature and, to a lesser extent, of steady-state photosynthesis at high temperature. Plant J 71:871-880. https://doi.org/10.1111/j.1365-313X.2012.05041.x

Yamori W, Suzuki K, Noguchi K, Nakai M, Terashima I (2006) Effects of Rubisco kinetics and Rubisco activation state on the temperature dependence of the photosynthetic rate in spinach leaves from contrasting growth temperatures. Plant Cell Environ 29:16591670. https:/doi.org/10.1111/j.1365-3040.2006.01550.x

Yamori W, Von Caemmerer S (2009) Effect of Rubisco activase deficiency on the temperature response of $\mathrm{CO}_{2}$ assimilation rate and Rubisco activation state: insights from transgenic tobacco with reduced amounts of Rubisco activase. Plant Physiol 151:2073-2082. https://doi.org/10.1104/pp.109.146514

Yin Z, Meng F, Song H, Wang X, Xu X, Yu D (2010) Expression quantitative trait loci analysis of two genes encoding rubisco activase in soybean. Plant Physiol 152:1625-1637. https://doi.org/10.1104/pp.109.148312

Yin Z, Zhang Z, Deng D, Chao M, Gao Q, Wang Y, Yang Z, Bian Y, Hao D, Xu C (2014) Characterization of RuBisCo activase genes in maize: an a-isoform gene functions alongside a $\beta$-isoform gene. Plant Physiol 164:2096-2106. https://doi.org/10.1104/pp.113.230854

Yoon DK, Ishiyama K, Suganami M, Tazoe Y, Watanabe M, Imaruoka S, Ogura M, Ishida H, Suzuki Y, Obara M, Mae T, Makino A (2020) Transgenic rice overproducing Rubisco exhibits increased yields with improved nitrogen-use efficiency in an experimental paddy field. Nat Food 1(2):134-139. https://doi. org/10.1038/s43016-020-0033-x

Zang X, Geng X, Liu K, Wang F, Liu Z, Zhang L, Zhao Y, Tian X, Hu Z, Yao Y (2017) Ectopic expression of TaOEP16-2-5B, a wheat plastid outer envelope protein gene, enhances heat and drought stress tolerance in transgenic Arabidopsis plants. Plant Sci 258:1-11. https://doi.org/10.1016/.jplantsci.2017.01.011

Zhang J, Du H, Chao M, Yin Z, Yang H, Li Y, Huang F, Yu D (2016) Identification of two bZIP transcription factors interacting with the promoter of soybean rubisco activase gene (GmRCAa). Front Plant Sci 7:628. https://doi.org/10.33 89/fpls.2016.00628

Zhang M, Li X, Yang Y, Luo Z, Liu C, Gong M, Zou Z (2015) An acidified thermostabilizing mini-peptide derived from the carboxyl extension of the larger isoform of the plant Rubisco activase. J Biotechnol 212:116-124. https://doi.org/10.1016/j.jbiotec.2015.08.021

Zhang N, Kallis RP, Ewy RG, Portis AR (2002) Light modulation of Rubisco in Arabidopsis requires a capacity for redox regulation of the larger Rubisco activase isoform. Proc Natl Acad Sci U S A 99:3330-3334. https://doi.org/10.1 073/pnas.042529999

Zhang N, Schürmann P, Portis AR (2001) Characterization of the regulatory function of the 46-kDa isoform of Rubisco activase from Arabidopsis. Photosynth Res 68:29-37. https://doi.org/10.1023/A:1011845506196

Zhang Z, Komatsu S (2000) Molecular cloning and characterization of cDNAs encoding two isoforms of ribulose-1, 5-bisphosphate carboxylase/oxygenase activase in rice (Oryza sativa L.). J Biochem 128(3):383-389. https://doi.org/1 0.1093/oxfordjournals.jbchem.a022765

Zhao G, Xu H, Zhang P, Su X, Zhao H (2017) Effects of 2, 4-epibrassinolide on photosynthesis and Rubisco activase gene expression in Triticum aestivum $\mathrm{L}$. seedlings under a combination of drought and heat stress. Plant Growth Regul 81(3):377-384. https://doi.org/10.1007/s10725-016-0214-7

\section{Publisher's Note}

Springer Nature remains neutral with regard to jurisdictional claims in published maps and institutional affiliations. 